\title{
Stark halfwidth trends along the homologous sequence of singly ionized noble gases
}

\author{
R. J. Peláez ${ }^{1}$, S. Djurović ${ }^{2}$, M. Ćirišan ${ }^{2}$, J. A. Aparicio ${ }^{1}$, and S. Mar ${ }^{1}$ \\ 1 Departamento de Física Teórica, Atómica y Óptica, Universidad de Valladolid, 47071 Valladolid, Spain \\ e-mail: apa@opt.uva.es \\ 2 Faculty of Sciences, Department of Physics, Trg Dositeja Obradovića 4, 21000 Novi Sad, Serbia
}

Received 3 February 2010 / Accepted 18 February 2010

\section{ABSTRACT}

\begin{abstract}
Aims. The aim of this work is to analyse experimental Stark halfwidths behaviour for the $\left({ }^{3} \mathrm{P}\right) \mathrm{ns}-\left({ }^{3} \mathrm{P}\right) \mathrm{np}$ and $\left({ }^{3} \mathrm{P}\right) \mathrm{np}-\left({ }^{3} \mathrm{P}\right) \mathrm{nd}$ transitions along the homologous sequence of single ionized noble gases. This kind of trend analysis can be useful for Stark halfwidths predictions and therefore for spectroscopic diagnostic of astrophysical plasmas.

Methods. The compilation of Stark halfwidths was done taking into account the measurements developed in the last decades. The experimental results and observed Stark halfwidth trends for different multiplets of ionized noble gases were compared with the modified semiempirical formula (MSE) calculations and other theoretical estimations.

Results. The analysis shows that the halfwidths of the spectral lines in all observed multiplets belonging to the same transitions have a similar trend along the homologous sequence. Stark halfwidths of $\left({ }^{3} \mathrm{P}\right) \mathrm{ns}-\left({ }^{3} \mathrm{P}\right) \mathrm{np}$ transitions are more or less constant, while those of $\left({ }^{3} \mathrm{P}\right) \mathrm{np}-\left({ }^{3} \mathrm{P}\right)$ nd transitions have a clear increasing slope. A qualitative explanation of the observed Stark halfwidth trends based on the energy level structure is also given.
\end{abstract}

Key words. plasmas - atomic data - line: profiles

\section{Introduction}

Investigation of the Stark broadening of ionic lines of noble gases is of great importance for the spectroscopy of both laboratory and astrophysical plasmas (Reyna et al. 2009). For example, atomic data of argon, krypton and xenon are useful for the spectral diagnostics of ITER (Skinner 2009). There is a number of astrophysical problems where Stark broadening data are of interest, like abundance determination, calculation of stellar opacities (Iglesias et al. 1990), interpretation and modelling of stellar spectra, stellar atmospheres modelling (Werner 1984) and investigations, estimation of the radiative transfer through the stellar plasma etc. The spectral line shape research has been additionally stimulated by the development of space astronomy, where an extensive amount of spectroscopy information has been collected; as well as softwares used for stellar atmosphere simulations, like TMAP (Werner et al. 2003), SMART (Sapar et al. 2009) etc., where a large amount of atomic and spectroscopic data are needed. Availability of these parameters will be useful for a further development of stellar atmosphere and evolution models (Leitherer 2010).

In the spectra of $\mathrm{O}, \mathrm{B}$ and $\mathrm{A}$ type stars as well as white dwarfs, a large number of singly and multiply charged ion lines has been observed (Peytremann 1972; Lanz et al. 1988; Popović et al. 1999). In the atmospheres of such stars, Stark broadening is the dominant pressure broadening mechanism. Besides, Stark broadening may be important in the atmospheres of relatively cool stars like Sun. Ionized noble gases are detected in many astronomic spectra. Neon is the most abundant element in the universe after $\mathrm{H}, \mathrm{He}, \mathrm{O}$ and $\mathrm{C}$. Ne II was found in the nucleus of spiral galaxy NGC 253 (Boeker et al. 1998), variable T Tauri stars (Lahuis et al. 2007) and Herbig-Haro objects (Lefloch et al. 2003). One of the most relevant roles of Ne II in astrophysics is in the study of creation and evolution of planetary systems. Indeed, Ne II was detected in young circumstelar disks of stars similar to the Sun, where planets may be forming (Pascucci et al. 2007). The optical spectra of early B-type stars contain a number of unblended Ar II lines (Lanz et al. 2008). Lanz et al. also analysed Ar II lines in the blue spectrum of $10 \mathrm{~B}$ mainsequence stars in the Orion association. They also derived a mean argon abundance using the observed Ar II spectra in HD 35299 star. Ar II lines were also observed in the Orion nebula (Lanz et al. 2008; Esteban et al. 2004). Keenan et al. (1990) analysed two Ar II lines in the blue spectrum of five bright B-type stars in the field to derive the argon abundance. The linelist used in computation of the synthetic spectra around each of the Ar II line is an update of the Kurucz (1994) linelist. Argon abundances were derived from the best fits between synthetic and observed spectra. Krypton was detected in the spectra of the interstellar medium (Cardelli \& Mayer 1997), galactic disc (Cartledge et al. 2003) and planetary nebulae (Dinerstein 2001). In this last case, the spectral information was used to understand the latest stages of the stellar evolution and nucleosynthesis processes (Dinerstein 2001). Ionized xenon was identified in $\mathrm{k}$ Cnc, 112 Herculis, HR 7245 and HR 7361 stars (Whitford 1962; Bidelman 1964; Adelman 1992; Sadakane et al. 2001). In Ryabchikova et al. (1999) Xe II spectrum was identified in hot Hg-Mn stars by 460.3, 484.4, $497.3 \mathrm{~nm}$ lines, while Sadakane et al. (2001) reports eleven spectral lines from 526.195 to $605.115 \mathrm{~nm}$ in the spectrum of Hg-Mn star 46 Aquilae (HD 186122). Xe II was also found in Hg-Mn star HR7143 (Bord et al. 2003). 
In the last years great efforts were made in the analysis of Stark parameters of singly ionized noble gases. For the last decades, the halfwidths of the most prominent lines were measured, most of them corresponding to $\left({ }^{3} \mathrm{P}\right) \mathrm{ns}-\left({ }^{3} \mathrm{P}\right) \mathrm{np}$ transitions ( $n=3$ for Ne II, $n=4$ for Ar II, $n=5$ for Kr II and $n=6$ for Xe II). Nowadays, the optical systems, especially light detectors, have a higher sensitivity and resolution, thus enabling the measurement of narrow and low intensity spectral lines. Therefore, both older and recent experimental results should be taken into account when performing an analysis. Most of the line halfwidths corresponding to $\left({ }^{3} \mathrm{P}\right) n \mathrm{~s}-\left({ }^{3} \mathrm{P}\right) n \mathrm{p}$ transitions were already measured, as well as a great number of line halfwidths corresponding to $\left({ }^{3} \mathrm{P}\right) n \mathrm{p}-\left({ }^{3} \mathrm{P}\right) n \mathrm{~d}$ transitions. For light atoms, like Ne II, the Griem's semiclassical model (1974) provides halfwidth values in a good agreement with the measurements (Peláez et al. 2008). For heavier atoms, like Kr II or Xe II, which have more complex spectra, the modified semiempirical formula (Dimitrijević \& Konjević 1980) gives acceptable results (del Val et al. 2008; Djurović et al. 2006).

Besides collecting the experimental data, regularities and systematic trends of the Stark parameters were analysed. Relations of the halfwidth and shift trends to atomic parameters or energy level configurations were studied. Wiese \& Konjević (1982) established three types of regularities or systematic behaviour of Stark parameters: i) regularities within a spectrum, which are either systematic trends along the spectral series of atoms and ions of simple structure or similarities within multiplets, supermultiplets and transition arrays for emitters with a more complex structure; ii) similarities for analogous transitions of homologous atoms and ions; and iii) systematic trends for a fixed transition of ions within an isoelectronic sequence.

In this paper, we deal with the analysis of Stark halfwidths along the homologous sequence of singly ionized noble gases. We analysed analogous spectral line halfwidths of homologous ions. "Analogous" indicates the same type of transition with only the principal quantum number changed, while "homologous" indicates ions with the same electric charge and similar energy levels structure in the outer shells. Due to these similarities, a gradual increase of the spectral line halfwidths i.e. systematic trends should be expected. Pittman \& Konjević (1986) first started this analysis of experimental Stark broadening data along the homologous sequence of singly ionized noble gases. Similar investigations were done in the papers by Miller et al. (1980) for other ionized atoms and Dimitrijević et al. (1987) and Vitel et al. (1988) for neutral atoms. There are three types of models providing a quantitative prediction of these trends. The first type was proposed by Konjević \& Pittman (1987) and Dimitrijević \& Popović (1989), where they derived an estimation of the Stark halfwidth behaviour along the homologous sequence depending on the effective quantum number. The second type was proposed by Purić et al. (1980). They found that Stark halfwidths and shifts of spectral lines emitted by nonhydrogenic atoms or ions, expressed in angular frequency units, depend on "effective ionization energy". This is the difference between the ionization energy and the energy of the upper transition level. They continued using this type of analysis in Puric et al. (1985, 1999, 2008), as well as Di Rocco (1990), Bertuccelli \& Di Rocco (1991, 1993). The third type of trend prediction model is Stark parameters dependence on nuclear charge number derived by Purić \& Lakićević (1982) and Purić et al. (1985). In the papers by Dimitrijević \& Konjević (1984), Dimitrijević \& Popović (1989) and Dimitrijević (1985) an analysis of the last two types of Stark parameters trend prediction models was performed. In these papers attention was drawn to the serious limitations of the application of Stark parameters dependence on the ionization energy proposed by Purić et al. (1980). Dimitrijević \& Konjević (1984) also explained the Stark parameters dependence on the nuclear charge number.

We follow two aims in this work. The first one is to make an analysis of the experimentally obtained Stark halfwidths along the homologous sequence of singly ionized noble gases. This is the same type of analysis as that performed in the paper of Pittman \& Konjević (1986). At that time, the number of available experimental data was meager. A similar situation existed for later analyses (Di Rocco 1990; Bertuccelli \& Di Rocco 1991). Nowadays, a large number of Stark parameters of the spectral lines emitted by singly ionized atoms of noble gases is available. This will be commented later in Sect. 3. Furthermore, recent experiments provide more precise data because the quality of experimental apparatus, especially the detection systems, has been significantly improved. This enables us to make a more comprehensive and more precise analysis. The second aim is to check the theoretical models for the two main transitions in the homologous sequence. Special attention was paid to the analysis of the Stark halfwidth results of lines emitted from singly ionized noble gases, obtained from experiments performed in the Laboratory of Plasma Spectroscopy group in Valladolid.

\section{Experiment}

Stark parameters of the lines of singly ionized noble gases were measured during the last decade in the Laboratory of Plasma Spectroscopy in Valladolid (LPSV). Results of Ne II Stark parameter measurements are presented in papers by del Val et al. (2000) and Peláez et al. (2008), results of Ar II in the paper by Aparicio et al. (1998), results of Kr II in papers by del Val et al. (2008) and Djurović et al. (2008) and results of Xe II in papers by Djurović et al. (2006) and Peláez et al. (2009ab). During the last few years, the detection and control systems in the laboratory were improved, but the power supply system and the discharge lamp have remained essentially the same. For this reason the plasma conditions, i.e. electron density and temperature, are similar for all the above mentioned experimental works. Experimental apparatus and plasma diagnostics are described elsewhere (del Val et al. 1998; Djurović et al. 2006). Only a short description of the experiment and data treatment will be given here.

The excitation unit contains a capacitor bank of $20 \mu \mathrm{F}$ charged up to approximately $9 \mathrm{kV}$. The mixture of helium, as a working gas, and several percents of the analysed gas (neon, argon, krypton or xenon) at a pressure of about $3 \mathrm{kPa}$ continuously flows through the discharge lamp. The lamp is a cylindrical tube of Pyrex glass, $175 \mathrm{~mm}$ in length and $19 \mathrm{~mm}$ in internal diameter. The percentage of the analysed gas mixed with the helium was adjusted to get sufficiently high spectral line intensities and at the same time have minimal or null self-absorption effect. The self-absorption was checked by means of a mirror placed behind the discharge lamp. Spectra were recorded with a spectrometer equipped with an optical multichannel analyzer (OMA) detector and later with an intensified charge-coupled device (ICCD). The spectrometer's instrumental function was estimated by introducing a laser beam $(632.85 \mathrm{~nm})$ into its entrance slit. The halfwidth of this line, approximately $12.5 \mathrm{pm}(4.1 \mathrm{pm} / \mathrm{channel})$ for the OMA and $7 \mathrm{pm}(2.3 \mathrm{pm} / \mathrm{channel})$ for the ICCD, was taken into account as the instrumental broadening. An incandescent calibrated lamp and a deuterium lamp were used to obtain the spectrometer's transmittance. 
A two wavelengths interferometric method was used for the electron density determination. The electron density was in the range of $(0.2-1.9) \times 10^{23} \mathrm{~m}^{-3}$ with an estimated experimental uncertainty of about $10 \%$. To verify these results, the profile of the He I $388.86 \mathrm{~nm}$ line in conjunction with Griem's (1974) theoretical model was used, in most cases. The electron temperature was determined by a Boltzmann-plot of appropriate spectral lines and was in the range of (16000-45000) $\mathrm{K}$ for all above mentioned experiments. The estimated uncertainties were about $15 \%$.

The experimental data treatment is explained in detail in our previous work (Djurović et al. 2006). A fitting procedure (Gigosos et al. 1994) was applied to the experimentally obtained spectrum to determine the total line halfwidth, the central position and the area of each spectral line profile. In order to obtain the Stark halfwidth from the total experimental halfwidth of the spectral line, a standard deconvolution procedure was employed (Davies \& Vaughan 1963). Other broadening mechanisms, like Doppler and instrumental broadening, were taken into account, while on the other hand van der Waals and resonance broadening were negligible for the plasma conditions in these experiments.

\section{Analysis of the Stark halfwidths for the $\left({ }^{3} \mathrm{P}\right) n s-\left({ }^{3} \mathrm{P}\right) n \mathrm{p}$ and $\left({ }^{3} \mathrm{P}\right) n \mathrm{p}-\left({ }^{3} \mathrm{P}\right) n \mathrm{~d}$ transitions}

The Stark halfwidth results for all available experimental data of noble gases from Ne II to Xe II, for the $\left({ }^{3} \mathrm{P}\right) n \mathrm{~s}-\left({ }^{3} \mathrm{P}\right) n \mathrm{p}$ and $\left({ }^{3} \mathrm{P}\right) n \mathrm{p}-\left({ }^{3} \mathrm{P}\right) n \mathrm{~d}$ transitions are presented graphically in Figs. 2 to 4 . For further analysis, Stark halfwidths have been expressed in angular frequency units to avoid the wavelength dependence. Results for Ne II (Fig. 1) are taken from Platiša et al. (1978), Pittman \& Konjević (1986), Konjević \& Pittman (1987), Purić et al. (1987), Uzelac et al. (1993), Blagojević et al. (1999), del Val et al. (2000), Milosavljević et al. (2001) and Peláez et al. (2008).

Results for Ar II (Fig. 2) are taken from Popenoe \& Shumaker (1965), Jalufka et al. (1966), Roberts (1966), Chapelle et al. (1968ab), Roberts (1968), Konjević et al. (1970), Klein (1973), Labat et al. (1974), Behringer \& Thoma (1978), Vaessen et al. (1985), Nick \& Helbig (1986), Pittman \& Konjević (1986), Vitel \& Skowronek (1987), Abbas et al. (1988), Djeniže et al. (1989), Dzierzega \& Musiol (1994), Pellerin et al. (1997), Aparicio et al. (1998) and Iglesias et al. (2006).

Results for $\mathrm{Kr}$ II (Fig. 3) are taken from Pittman \& Konjević (1986), Vitel \& Skowronek (1987), Uzelac \& Konjević (1989), Lesage et al. (1989), Bertuccelli \& Di Rocco (1991), Milosavljević et al. (2000), de Castro et al. (2001), del Val et al. (2008) and Djurović et al. (2008).

Results for Xe II (Fig. 4) are taken from Miller et al. (1982), Richou et al. (1984), Nick \& Helbig (1986), Pittman \& Konjević (1986), Vitel \& Skowronek (1987), Manola et al. (1988), Lesage et al. (1989), Konjević \& Uzelac (1990), Bertuccelli et al. (1991a,b), Gigosos et al. (1994) and Djurović et al. (2006).

All above mentioned results except for the most recent ones, are critically reviewed in the papers by Konjević \& Wiese (1976), Konjević et al. (1984), Konjević \& Wiese (1990), Konjević et al. (2002) and Lesage (2009). These results were obtained in many different experiments under very different plasma conditions, i.e. for electron densities in the range of $2 \times 10^{22} \mathrm{~m}^{-3}-2.7 \times 10^{24} \mathrm{~m}^{-3}$ and electron temperatures in the range of $8000-82000 \mathrm{~K}$. For comparison, the results were normalised to an electron density of $10^{23} \mathrm{~m}^{-3}$, using linear halfwidth-electron density dependence, and the electron
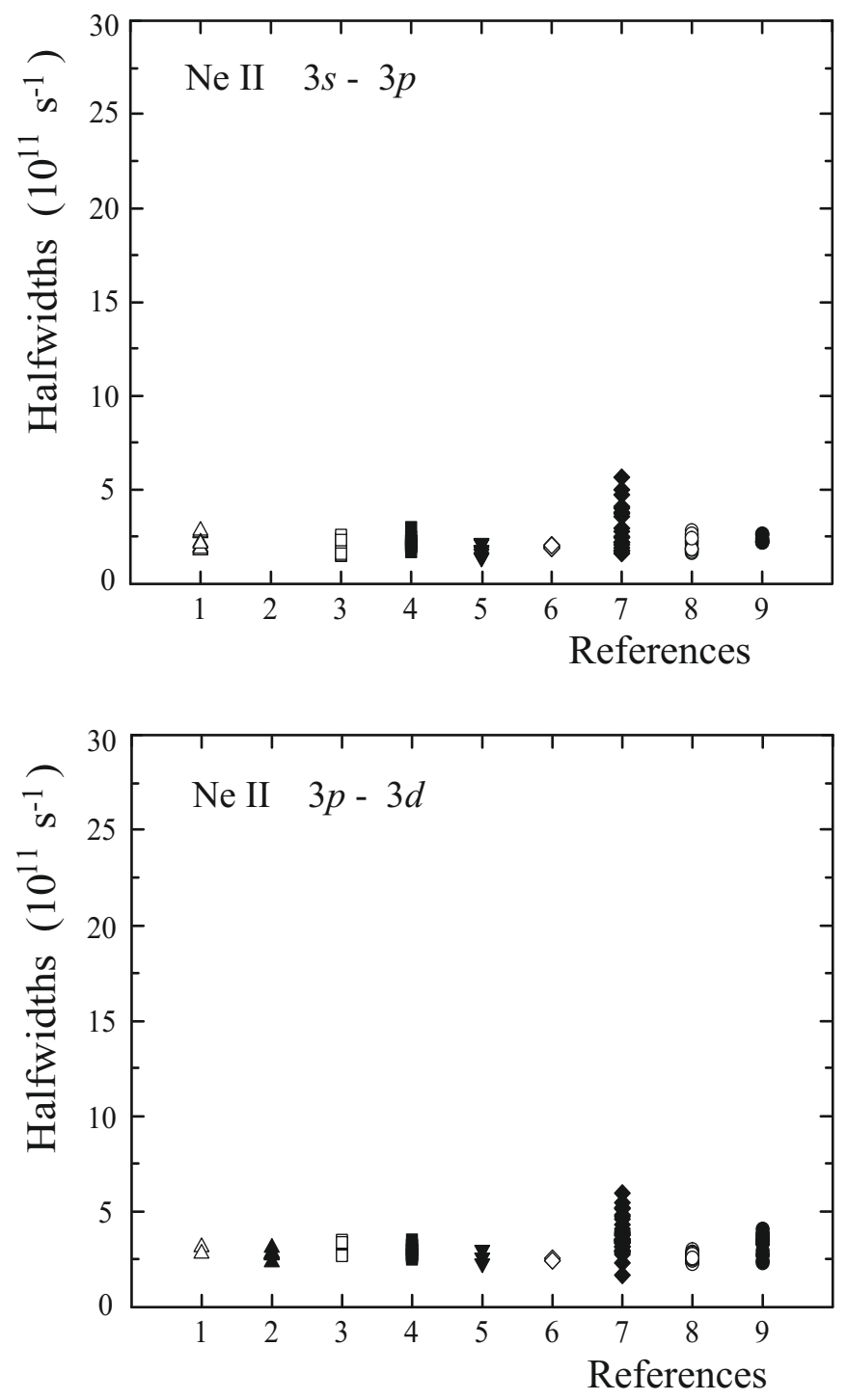

Fig. 1. Experimental Ne II Stark halfwidth data for the $\left({ }^{3} \mathrm{P}\right) 3 \mathrm{~s}-\left({ }^{3} \mathrm{P}\right) 3 \mathrm{p}$ and $\left({ }^{3} \mathrm{P}\right) 3 \mathrm{p}-\left({ }^{3} \mathrm{P}\right) 3 \mathrm{~d}$ transitions. References: $1-$ Platiša et al. (1978), 2- Pittman \& Konjević (1986), 3- Konjević \& Pittman (1987), 4- Purić et al. (1987), 5- Uzelac et al. (1993), 6- Blagojević et al. (1999), 7- del Val et al. (2000), 8- Milosavljević et al. (2001) and 9- Peláez et al. (2008).

temperature of $28000 \mathrm{~K}$ using the $T_{\mathrm{e}}^{-1 / 2}$ halfwidth dependence. For the same reason, the halfwidth results in Figs. 1-5 are presented normalised in the same way.

All Ne II Stark halfwidth results (Fig. 1) agree within the experimental errors for both the $\left({ }^{3} \mathrm{P}\right) n \mathrm{~s}-\left({ }^{3} \mathrm{P}\right) n \mathrm{p}$ and $\left({ }^{3} \mathrm{P}\right) n \mathrm{p}-\left({ }^{3} \mathrm{P}\right) n \mathrm{~d}$ transitions. There is a certain dispersion of the del Val et al. (2000) results, but this was explained in the paper by Peláez et al. (2008). More disagreement can be seen among the results of Ar II, Kr II and Xe II (Figs. 2-4), which is expected due to their more complex spectra. Halfwidth values for the Ar II, $4 s-4 p$ transitions (Fig. 2) vary for about $\pm 50 \%$ around the average value. Exceptions are the results in Jalufka et al. (1966) and Abbas et al. (1988), which are too high and some results in Vaessen et al. (1985) and Nick \& Helbig (1986), which are slightly lower than the other results. The Ar II halfwidth results corresponding to $4 \mathrm{p}-4 \mathrm{~d}$ transitions (Fig. 2) vary for about $\pm 60 \%$ around the average value, with the exception of two results in Pellerin et al. (1997), which are too low. There is a similar situation with the Kr II results (Fig. 3). The results for the 

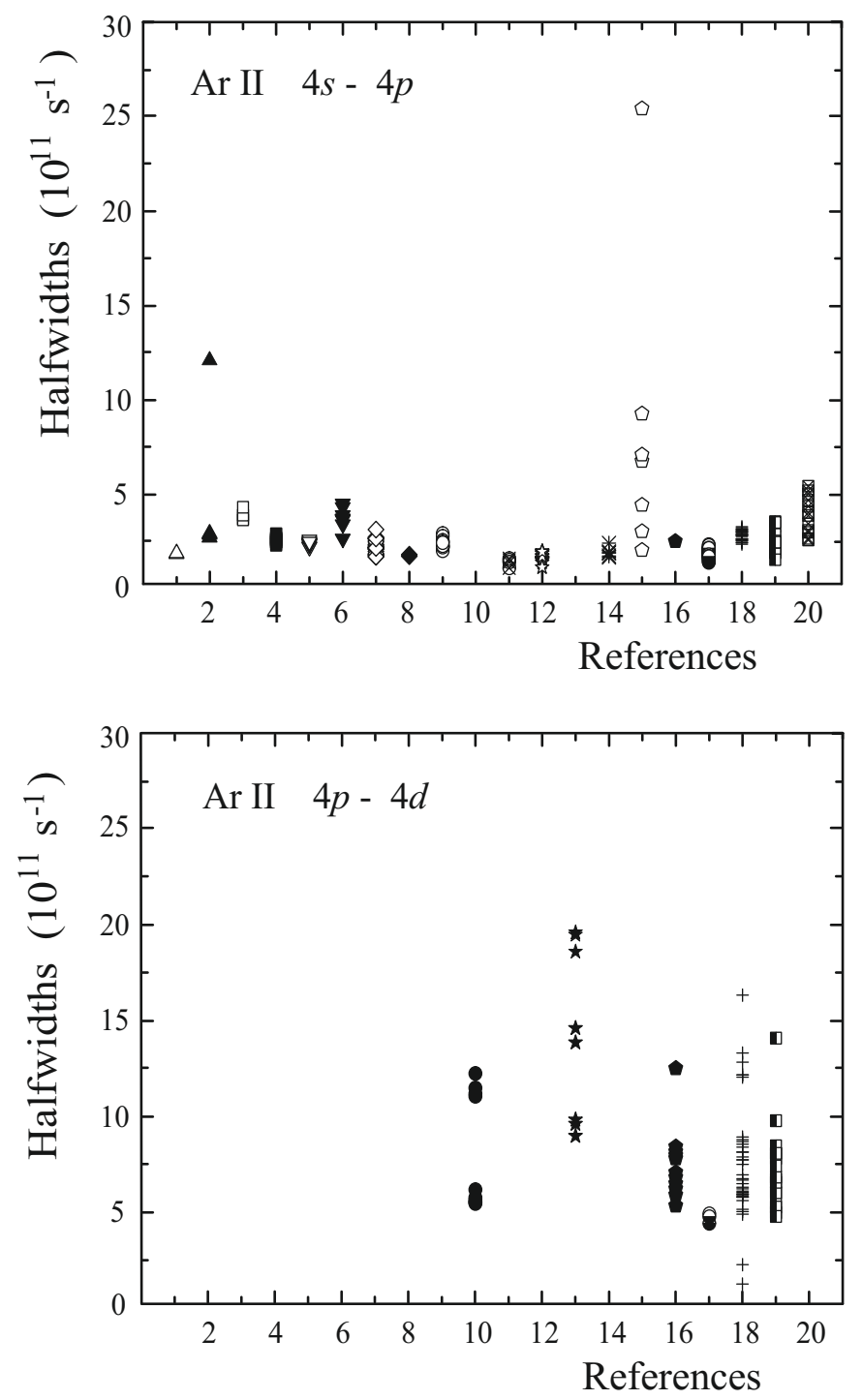

Fig. 2. Experimental Ar II Stark halfwidth data for the $\left({ }^{3} \mathrm{P}\right) 4 \mathrm{~s}-\left({ }^{3} \mathrm{P}\right) 4 \mathrm{p}$ and $\left({ }^{3} \mathrm{P}\right) 4 \mathrm{p}-\left({ }^{3} \mathrm{P}\right) 4 \mathrm{~d}$ transitions. References: $1-$ Popenoe \& Shumaker (1965), 2- Jalufka et al. (1966), 3- Roberts (1966), 4- Chapelle et al. (1968a), 5- Chapelle et al. (1968b), 6- Roberts (1968), 7- Konjević et al. (1970), 8- Klein (1973), 9- Labat et al. (1974), 10- Behringer \& Thoma (1978), 11- Vaessen et al. (1985), 12- Nick \& Helbig (1986), 13- Pittman \& Konjević (1986), 14- Vitel \& Skowronek (1987), 15- Abbas et al. (1988), 16- Djeniže et al. (1989), 17- Dzierzega \& Musiol (1994), 18- Pellerin et al. (1997), 19- Aparicio et al. (1998) and 20- Iglesias et al. (2006).

Xe II, $6 s-6 p$ transitions (Fig. 4) vary for about $\pm 40 \%$ around the average value. There are only a few results from Miller et al. (1982) and Bertuccelli et al. (1991a) that are too high. The Xe II halfwidth results corresponding to $6 \mathrm{p}-6 \mathrm{~d}$ transitions (Fig. 4) vary for about $\pm 45 \%$ around the average value. Here it should be mentioned that for the $\mathrm{Kr}$ II, $5 \mathrm{p}-5 \mathrm{~d}$ transitions and the $\mathrm{Xe} \mathrm{II,}$ $6 p-6 d$ transitions the number of the existing data is too small to be able to make some general conclusions. However, a large data dispersion is expected for ionized noble gases because of their very complex spectra.

A general trend of the Stark halfwidths along the sequence of ionized noble gases is analysed. For this analysis, a graphical representation of the results as shown in Fig. 5 can be very appropriate. In this analysis, only experimental data from
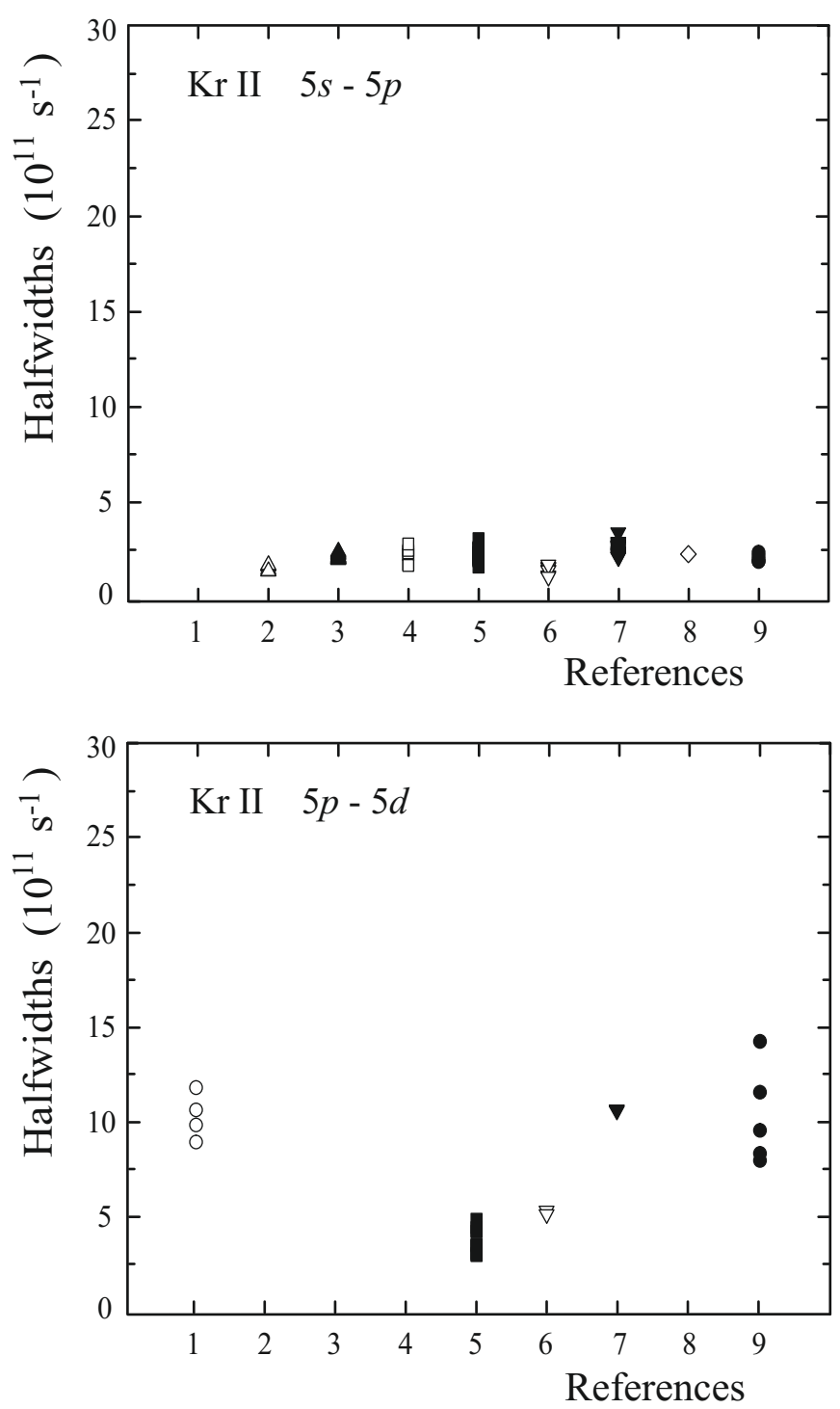

Fig. 3. Experimental Kr II Stark halfwidth data for the $\left({ }^{3} \mathrm{P}\right) 5 \mathrm{~s}-\left({ }^{3} \mathrm{P}\right) 5 \mathrm{p}$ and $\left({ }^{3} \mathrm{P}\right) 5 \mathrm{p}-\left({ }^{3} \mathrm{P}\right) 5 \mathrm{~d}$ transitions. References: $1-$ Pittman \& Konjević (1986), 2- Vitel \& Skowronek (1987), 3- Uzelac \& Konjević (1989), 4- Lesage et al. (1989), 5- Bertuccelli \& Di Rocco (1991), 6- Milosavljević et al. (2000), 7- del Castro et al. (2001), 8- del Val et al. (2008) and 9- Djurović et al. (2008).

experiments performed in LPSV were used. These data are given in del Val et al. (2000) and Peláez et al. (2008) for Ne II, in Aparicio et al. (1998) for Ar II, in de Castro et al. (2001) and Djurović et al. (2008) for Kr II and in Gigosos et al. (1994) and Djurović et al. (2006) for Xe II.

The reasons we used only LPSV results for the analysis are as follows: i) there are a lot of available results for the analysis, except for the Kr II 5p-5d and Xe II 6p-6d transitions; ii) it exists a dispersion of the experimental data and some results do not agree well with most other results; iii) according for a further analysis only high quality results should be considered, i.e. results with an estimated accuracy B, which was the highest accuracy for the considered results in review papers (Konjević \& Wiese 1976; Konjević et al. 1984; Konjević \& Wiese 1990; Konjević et al. 2002; and Lesage 2009); iv) all LPSV results (Gigosos et al. 1994; Aparicio et al. 1998; del Val et al. 2000; and del Castro et al. 2001) were estimated with accuracy B, except the latest ones (Djurović et al. 2006, 2008; 

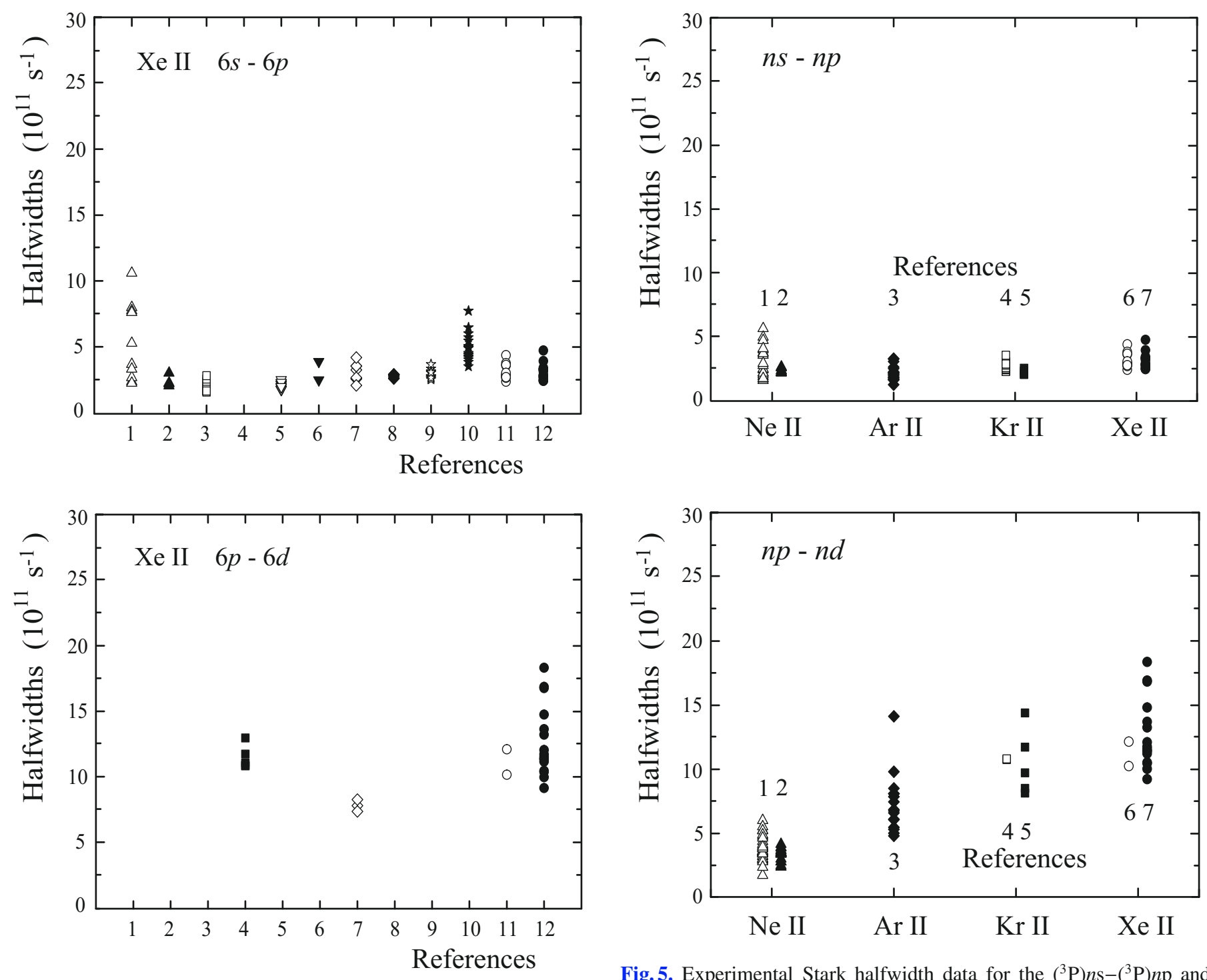

Fig. 4. Experimental Xe II Stark halfwidth data for the $\left({ }^{3} \mathrm{P}\right) 6 \mathrm{~s}-\left({ }^{3} \mathrm{P}\right) 6 \mathrm{p}$ and $\left({ }^{3} \mathrm{P}\right) 6 \mathrm{~s}-\left({ }^{3} \mathrm{P}\right) 6 \mathrm{p}$ transitions. References: $1-$ Miller et al. (1982), 2- Richou et al. (1984), 3- Nick \& Helbig (1986), 4- Pittman \& Konjević (1986), 5- Vitel \& Skowronek (1987), 6- Manola et al. (1988), 7- Lesage et al. (1989), 8- Konjević \& Uzelac (1990), 9- Bertuccelli et al. (1991a, 10- Bertuccelli et al. 1991b), 11- Gigosos et al. (1994) and 12- Djurović et al. (2006).

and Peláez et al. 2008), which have not yet been taken into consideration; v) all mentioned LPSV results agree very well with other high accuracy results and are sufficient for representing the general behaviour of the Stark halfwidths in the graph without having a great number of mutually overlapping points; vi) there is a significant number of already published LPSV results, sufficient for the analysis and vii) and, maybe the most important, all LPSV experiments were performed under similar plasma conditions, so it is not necessary to make the halfwidthtemperature dependence normalisation for the large temperature interval, which is not as precise as the one for halfwidth-electron density dependence.

For all these reasons the analysis will be more precise and easily understandable. From Fig. 5 it can be clearly seen that for $n \mathrm{~s}-n \mathrm{p}$ transitions Stark halfwidths are almost constant along the considered homologous sequence, while for $n \mathrm{p}-n \mathrm{~d}$ transitions they clearly increase. The conclusion is the same even if

Fig. 5. Experimental Stark halfwidth data for the $\left({ }^{3} \mathrm{P}\right) n \mathrm{~s}-\left({ }^{3} \mathrm{P}\right) n \mathrm{p}$ and $\left({ }^{3} \mathrm{P}\right) n \mathrm{p}-\left({ }^{3} \mathrm{P}\right) n \mathrm{~d}$ transitions along the homologous sequence. References: 1- del Val et al. (2000), 2- Peláez et al. (2008), 3- Aparicio et al. (1998), 4- del Castro et al. (2001), 5- Djurović et al. (2008), 6- Gigosos et al. (1994) and 7- Djurović et al. (2006).

experimental errors and data dispersion are taken into account. In Wiese \& Konjević (1982) it was found that Stark halfwidths of the spectral lines belonging to the same transition array normally have values within a range of about $\pm 40 \%$. An analysis of the results from Fig. 5 shows that: i) Stark halfwidths of Ne II from del Val et al. (2000) are within $\pm 54 \%$, for both $n s-n p$ and $n \mathrm{p}-n$ d transitions, while data from Peláez et al. (2008) are within $\pm 14 \%$ for $n \mathrm{~s}-n \mathrm{p}$ and $\pm 29 \%$ for $n \mathrm{p}-n \mathrm{~d}$ transitions. The comment about a relatively high deviation of the results by del Val et al. (2000) was already given above, while a very low deviation for $n s-n p$ transitions in Peláez et al. (2008) can be explained by a small number of data. ii) Halfwidths of Ar II from Aparicio et al. vary for about $\pm 47 \%$ from the average value for both observed transitions. If we exclude only one highly positioned experimental point for the $n \mathrm{p}-n \mathrm{~d}$ transition (Fig. 5), the variations are lower than $\pm 40 \%$. iii) All results for $\mathrm{Kr}$ II (de Castro et al. 2001 and Djurović et al. 2008) are within $\pm 29 \%$. iv) A similar situation is found for the results for Xe II (Gigosos et al. 1994; and Djurović et al. 2008), where the variation of line halfwidths is about $\pm 35 \%$. Our final conclusion is that the present Stark data 
satisfy the regular behaviour for transition arrays established in Wiese \& Konjević (1982), and they are valid for this kind of analysis.

\section{Multiplet by multiplet Stark halfwidth analysis}

For our multiplet by multiplet analysis, we took only data from Gigosos et al. (1994), Aparicio et al. (1998), del Val et al. (2000), de Castro et al. (2001), Djurović et al. (2006, (2008) and Peláez et al. (2008). A significant number of results in these papers enabled us to make this analysis (see Table 1). The evolution of the Stark halfwidths for different homologous multiplets of the $\left({ }^{3} \mathrm{P}\right) n \mathrm{~s}-\left({ }^{3} \mathrm{P}\right) n \mathrm{p}$ transition is shown in Fig. 6. Stark halfwidth results for Ne II, Ar II, Kr II and Xe II are grouped by multiplets and data sources. Experimental errors, which were taken from the corresponding references, are given as error bars only for some experimental points as an illustration of experimental uncertainty.

From Fig. 6 it is evident that the dispersion of the experimental points is in most cases larger than the estimated experimental errors. The error bars in Fig. 6 denote the experimental errors for particular experimental results, which do not exceed $20 \%$ to $30 \%$, if we exclude the results for Ne II by del Val et al. (2000). The dispersion of all other results is within $\pm 40 \%$, which was already established in Wiese \& Konjević (1982) as the regular behaviour of the Stark halfwidth variation within the transition array. The full line in Fig. 6 represents the linear fit of the average Stark halfwidth values for all analysed multiplets from Ne II to Xe II. The slope of the Stark halfwidth increase along the homologous sequence is small. The ratio of the fitted Xe II Stark halfwidth value over that of $\mathrm{Ne}$ II is 1.25 , i.e. the difference between the Xe II and Ne II values is $25 \%$, which is within the experimental errors of the obtained results. Results from del Val et al. (2000) were excluded from this analysis as well, but including them would only give an even smaller slope. In conclusion, the increase of the Stark halfwidths along the homologous sequence is very small for the $\left({ }^{3} \mathrm{P}\right) n \mathrm{~s}-\left({ }^{3} \mathrm{P}\right) n \mathrm{p}$ transitions. In addition, one can observe that the halfwidths of the spectral lines belonging to the ${ }^{4} \mathrm{P}-{ }^{4}$ (DPS $)^{\mathrm{O}}$ multiplets are more dispersed than the halfwidths from ${ }^{2} \mathrm{P}-{ }^{2}(\mathrm{DPS})^{\mathrm{o}}$ multiplets.

In Fig. 6, all measured Stark halfwidth data of the lines belonging to multiplets ${ }^{2} \mathrm{P}-{ }^{2} \mathrm{D}^{\mathrm{o}},{ }^{2} \mathrm{P}-{ }^{2} \mathrm{P}^{\mathrm{o}},{ }^{2} \mathrm{P}-{ }^{2} \mathrm{~S}^{\mathrm{o}},{ }^{4} \mathrm{P}-{ }^{4} \mathrm{D}^{\mathrm{o}},{ }^{4} \mathrm{P}-{ }^{4} \mathrm{P}^{\mathrm{o}}$ and ${ }^{4} \mathrm{P}-{ }^{4} \mathrm{~S}^{0}$ are presented together. Here many points overlap each other. In order to analyse the relations between the results from different multiplets along the homologous sequence of singly ionized noble gases, the average value of Stark halfwidths for each observed multiplet was calculated and is presented in Fig. 7. Here the obtained results show no particular dependence on the multiplets. There is a small increase of the Stark halfwidth values along the homologous sequence, similar to that in Fig. 6. The ratio of the fitted Xe II average Stark halfwidth value over the Ne II one is 1.30 , in this case. The difference between the $\mathrm{Xe}$ II and Ne II values is $30 \%$, which is still within the experimental error or the expected variation within the transition array (Wiese \& Konjević 1982).

The evolution of the Stark halfwidths for different homologous multiplets of the $\left({ }^{3} \mathrm{P}\right) n \mathrm{p}-\left({ }^{3} \mathrm{P}\right) n$ d transition is shown in Fig. 8 in the same way as the results in Fig. 6 . The increase of the Stark halfwidth from Ne II to Xe II is obvious (full fitting line in Fig. 8). The ratio of the fitted Xe II Stark halfwidth value over the Ne II one is 3.08. All results show a regular Stark halfwidth behaviour for transition arrays, i.e. their variation for each element is within $\pm 50 \%$. The results for the Ar II (Aparicio et al. 1998) $357.662 \mathrm{~nm}$ line corresponding to the $\left({ }^{3} \mathrm{P}\right) 4 \mathrm{p}^{4} \mathrm{D}^{\mathrm{o}}-\left({ }^{3} \mathrm{P}\right) 4 \mathrm{~d}^{4} \mathrm{~F}$
Table 1. Numbers and sources of the spectral lines used for the analysis.

\begin{tabular}{lccl}
\hline \hline & $\left({ }^{3} \mathrm{P}\right) n \mathrm{~s}-\left({ }^{3} \mathrm{P}\right) n \mathrm{p}\left({ }^{3} \mathrm{P}\right) n \mathrm{p}-\left({ }^{3} \mathrm{P}\right) n \mathrm{~d}$ & Reference \\
\hline Ne II & 17 & 9 & del Val et al. (2000) \\
& 10 & 16 & Peláez et al. (2008) \\
Ar II & 15 & 14 & Aparicio et al. (1998) \\
Kr II & 17 & 1 & de Castro et al. (2001) \\
& 3 & 3 & Djurović et al. (2008) \\
Xe II & 11 & 2 & Gigosos et al. (1994) \\
& 15 & 6 & Djurović et al. (2006) \\
\hline TOTAL & 88 & 52 & \\
\hline
\end{tabular}

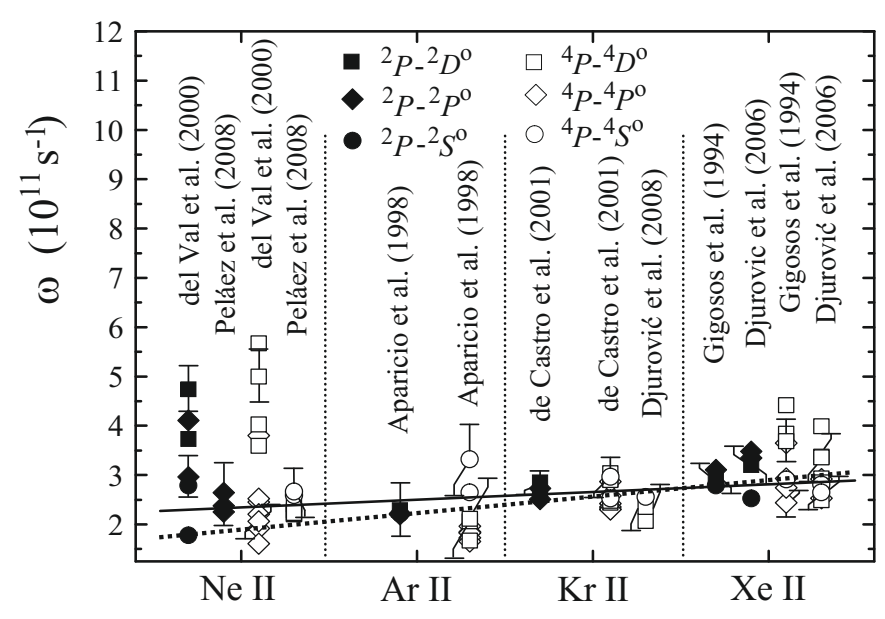

Fig. 6. Evolution of the Stark halfwidths for different homologous multiplets of the $\left({ }^{3} \mathrm{P}\right) n \mathrm{~s}-\left({ }^{3} \mathrm{P}\right) n \mathrm{p}$ transition. The linear fit of experimental results is presented by a full line and the MSE calculations (Dimitrijević \& Konjević 1980) by a dotted line.

transition, for the $\mathrm{Kr}$ II (Djurović et al. 2008) $387.544 \mathrm{~nm}$ line from the $\left({ }^{3} \mathrm{P}\right) 5 \mathrm{p}^{4} \mathrm{~S}^{\mathrm{o}}-\left({ }^{3} \mathrm{P}\right) 5 \mathrm{~d}^{4} \mathrm{P}$ transition and for the Xe II (Djurović et al. 2006), $390.791 \mathrm{~nm}$ line from the $\left({ }^{3} \mathrm{P}\right) 6 \mathrm{p}^{4} \mathrm{D}^{\mathrm{o}}-\left({ }^{3} \mathrm{P}\right) 6 \mathrm{~d}^{4} \mathrm{~F}$ transition were excluded from this analysis. These three results correspond to the high positioned points in Fig. 8. The results for Kr II and Xe II are $60 \%$ higher than the average (fitted) values, while the result for Ar II is twice as high compared to the fitted halfwidth value. It is important to point out that these results are not bad results. In all three cases, these deviations can be easily explained by the existence of a perturbing level very close to the upper transition level. Some irregular behaviour of the Stark parameters is expected the complex spectra like spectra of noble gases. For example, some irregularities in the Xe II spectra are described in Peláez et al. (2009a).

The analysis of the relations between the results from different multiplets of the $\left({ }^{3} \mathrm{P}\right) n \mathrm{p}-\left({ }^{3} \mathrm{P}\right) n \mathrm{~d}$ transition, similar to that given in Fig. 7, is much clearer here and shows the same Stark halfwidth behaviour as already shown in Fig. 7.

In the previous analysis, an $L S$ coupling scheme notation was used. For the Ne II, Ar II and Kr II multiplets the NIST data base notation was used, while for the Xe II multiplets the $L S$ coupling notation from Striganov and Sventitskii tables (1968) was employed. It is well known that Xe II spectra are much better described by the $j K$ coupling scheme (Hansen $\&$ Person 1987), but for an easier comparison of the multiplets the $L S$ coupling notation was used in Figs. 6-8. Furthermore it should be pointed out in for this type of analysis that the usually used coupling schemes cannot describe the complex spectra well, such as spectra of the ionized noble gases. There are papers devoted to the analysis of the energy-levels purity for 


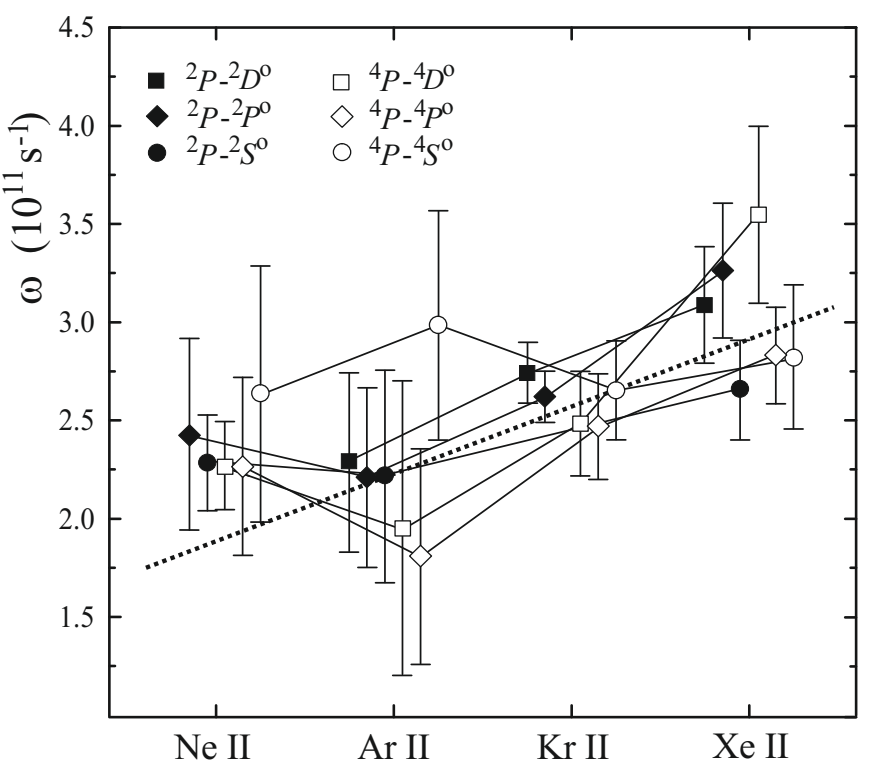

Fig. 7. Average Stark halfwidths for different homologous multiplets in the $\left({ }^{3} \mathrm{P}\right) n \mathrm{~s}-\left({ }^{3} \mathrm{P}\right) n \mathrm{p}$ transition. The MSE calculation (Dimitrijević \& Konjević 1980) is presented by a dotted line.

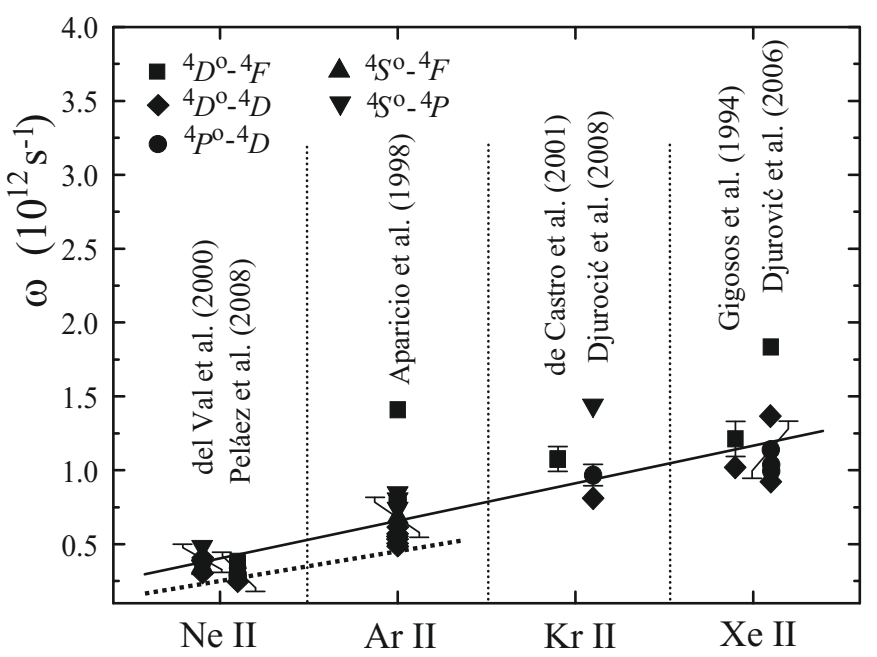

Fig. 8. Evolution of the Stark halfwidth for different homologous multiplets in the $\left({ }^{3} \mathrm{P}\right) n \mathrm{p}-\left({ }^{3} \mathrm{P}\right) n \mathrm{~d}$ transition. The linear fit of experimental results is presented by a full line and the MSE calculations (Dimitrijević \& Konjević 1980) by a dotted line.

particular coupling schemes. The purity of the Ne II levels relevant for this work is greater than $90 \%$ (Hansen \& Persson 1973; Kramida \& Nave 2006). For Ar II, Minnhagen (1962) concludes that the $L S$ coupling is good enough for the $4 \mathrm{~s}, 4 \mathrm{p}$ and $4 \mathrm{~d}$ configurations. For $\mathrm{Kr}$ II and $\mathrm{Xe}$ II, the $L S$ coupling scheme is not of a high purity. For example, for the Kr II level with an energy of $115092.012 \mathrm{~cm}^{-1}$ the purity of the representative term $\left({ }^{3} \mathrm{P}\right) 5 \mathrm{~s}^{4} \mathrm{P}_{3 / 2}$, is only 59\% (Sugar \& Musgrove 1991). For the $5 \mathrm{p}$ and $5 \mathrm{~d}$ configurations in $\mathrm{Kr}$ II, the purity calculations for different coupling schemes have not yet been found. The Xe II spectra are even more complex. Here, the energy levels are not described with a high purity neither for the $L S$ nor for the intermediate $j K$ coupling (Hansen \& Persson 1987; Sherbini \& Zaki 1978). Furthermore, for Xe II different parent terms and ionization potentials may exist, as shown in the NIST database.
These facts should be taken into account in both experimental and theoretical analyses.

\section{Theoretical consideration}

For theoretical explanation of the Stark halfwidth evolution, for different homologous multiplets of $\left({ }^{3} \mathrm{P}\right) n \mathrm{~s}-\left({ }^{3} \mathrm{P}\right) n \mathrm{p}$ and $\left({ }^{3} \mathrm{P}\right) n \mathrm{p}-\left({ }^{3} \mathrm{P}\right) n \mathrm{~d}$ transitions, modified semiempirical formula MSE (Dimitrijević \& Konjević 1980) was used:

$$
\begin{aligned}
w_{\text {th }} & =N_{\mathrm{e}} \frac{8 \pi}{3} \frac{\hbar^{2}}{m^{2}}\left(\frac{2 m}{\pi k T}\right)^{1 / 2} \frac{\pi}{\sqrt{3}}\left[R_{l_{i}, l_{i+1}}^{2} \tilde{g}\left(\frac{E}{\Delta E_{l_{i}, l_{i+1}}}\right)\right. \\
+ & R_{l_{i}, l_{i-1}}^{2} \tilde{g}\left(\frac{E}{\Delta E_{l_{i}, l_{i-1}}}\right)+R_{l_{f}, l_{f+1}}^{2} \tilde{g}\left(\frac{E}{\Delta E_{l_{f}, l_{f+1}}}\right)+R_{l_{f}, l_{f-1}}^{2} \tilde{g}\left(\frac{E}{\Delta E_{l_{f}, l_{f-1}}}\right) \\
& \left.+\sum_{i^{\prime}}\left(R_{i i^{\prime}}^{2}\right)_{\Delta n \neq 0} g\left(\frac{3 k T n_{i}^{3}}{4 Z^{2} E_{\mathrm{H}}}\right)+\sum_{f^{\prime}}\left(R_{f f^{\prime}}^{2}\right)_{\Delta n \neq 0} g\left(\frac{3 k T n_{f}^{3}}{4 Z^{2} E_{\mathrm{H}}}\right)\right],
\end{aligned}
$$

where $E=3 k T / 2$ is the energy of the perturbing electron, $\Delta E_{l l^{\prime}}=\left|E_{l}-E_{l^{\prime}}\right|$ is the energy difference between the levels $l$ and $l^{\prime}$. Two types of matrix elements are calculated as

$$
\begin{aligned}
R_{l l^{\prime}}^{2} \approx & \left(\frac{3 n^{*}}{2 Z}\right)^{2} \frac{\max \left(l, l^{\prime}\right)}{2 l+1}\left[n^{* 2}-\max \left(l, l^{\prime}\right)^{2}\right] \Phi^{2} \\
& \sum_{j^{\prime}}\left(R_{j j^{\prime}}^{2}\right)_{\Delta n \neq 0} \approx\left(\frac{3 n_{j}^{*}}{2 Z}\right)^{2} \frac{1}{9}\left(n_{j}^{* 2}+3 l_{j}^{2}+3 l_{j}+11\right),
\end{aligned}
$$

where $n_{j}^{*}$ is the effective principal quantum number (Griem 1964)

$n_{j}^{*}=\left(\frac{Z^{2} E_{\mathrm{H}}}{E_{\mathrm{I}}-E_{j}}\right)^{1 / 2}$,

$E_{\mathrm{H}}$ and $E_{\mathrm{I}}$ are the ionization energies for hydrogen and the observed ion respectively, $l_{j}$ is the orbital angular momentum quantum number of the upper or lower energy state of the observed transition, $Z$ is the charge number, while the factor $\Phi^{2}$ (Bates \& Damgaard 1949) is calculated, but it can also be found tabulated in Oertel \& Shomo (1968). The Gaunt factor $\tilde{g}(x)$ is calculated as

$\tilde{g}(x)=0.7-\frac{1.1}{Z}+g(x)$

where $g(x)=0.20$ for $x \leqslant 2$ and $g(x)=0.24,0.33,0.56,0.98$ and 1.33 for $x=3,5,10,30$ and 100. At high temperatures of $3 k T / 2 \Delta E>50$, all Gaunt factors are calculated in accordance with Griem et al. (1962):

$\tilde{g}_{j^{\prime} j}=g_{j^{\prime} j}=\frac{\sqrt{3}}{\pi}\left[\frac{1}{2}+\ln \left(\frac{2 Z k T}{n_{j}^{2} \Delta E_{j^{\prime} j}}\right)\right]$.

Compared with the semiempirical calculations (Griem 1968), in the modified semiempirical formula transitions with $\Delta n=0$ are separated (Dimitrijević \& Konjević 1980). In this case it is necessary to know only two perturbing levels, $l+1$ and $l-1$, for both the upper and the lower transition energy level. For semiempirical calculations (Griem 1968) the complete set of perturbing energy levels is required.

For this analysis, we also considered the theoretical data obtained from the simplified modified semiempirical formula 
Eq. (1) derived in Dimitrijević \& Konjević (1987):

$$
\begin{aligned}
\omega(\AA)= & 2.2151 \times 10^{-8} \frac{\lambda^{2}(\mathrm{~cm}) N_{\mathrm{e}}\left(\mathrm{cm}^{-3}\right)}{T_{\mathrm{e}}^{1 / 2}(\mathrm{~K})} \\
& \times\left(0.9-\frac{1.1}{z}\right) \sum_{j=i, f}\left(\frac{3 n_{j}^{*}}{2 Z}\right)^{2}\left(n_{j}^{* 2}-l_{j}^{2}-l_{j}-1\right) .
\end{aligned}
$$

Equation (6) was obtained for the situations where very close perturbing levels do not exist $E / \Delta E_{j j^{\prime}} \leq 2$ and where $\Phi^{2}=1$ is a reasonable assumption for $\Delta n=0$ (Griem 1974). Under these conditions the ratio

$$
\frac{\omega\left(\mathrm{s}^{-1}\right)}{\sum_{j=i, f} n_{j}^{* 2}\left(n_{j}^{* 2}-l_{j}^{2}-l_{j}-1\right)},
$$

should be constant for the lines of the same homologous transitions (Konjević \& Pittman 1987). The normalisation factor:

$$
\sum_{j=i, f} n_{j}^{* 2}\left(n_{j}^{* 2}-l_{j}^{2}-l_{j}-1\right),
$$

is taken from Eq. (6).

Dimitrijević \& Popović (1989) obtained another normalisation factor with Eqs. (5) and (6). They assumed a relation between the transition energy levels and the ionization energy as

$E_{j}=a_{j}+b_{j} E_{\mathrm{I}}$,

where coefficients $a_{j}$ and $b_{j}$ should be determined empirically for the analogous energy levels within the homologous sequence. If the contribution of the lower transition level is neglected, the normalisation factor

$$
\frac{E_{\mathrm{H}}}{E_{\mathrm{I}}\left(1-b_{i}\right)-a_{i}}\left(\frac{4 E_{\mathrm{H}}}{E_{\mathrm{I}}\left(1-b_{i}\right)-a_{i}}-l_{i}^{2}-l_{i}-1\right) \text {, }
$$

can be derived and the ratio

$$
\frac{\omega\left(\mathrm{s}^{-1}\right)}{\frac{E_{\mathrm{H}}}{E_{\mathrm{I}}\left(1-b_{i}\right)-a_{i}}\left(\frac{4 E_{\mathrm{H}}}{E_{\mathrm{I}}\left(1-b_{i}\right)-a_{i}}-l_{i}^{2}-l_{i}-1\right)}
$$

should also be constant for all the lines along the homologous sequence. Equation (6) in combination with (10) shows an explicit relation between the Stark halfwidths and the ionization energy.

\section{Comparison of the experimental and calculated theoretical Stark halfwidth data}

For the $\left({ }^{3} \mathrm{P}\right) n \mathrm{~s}-\left({ }^{3} \mathrm{P}\right) n \mathrm{p}$ transitions, the MSE calculations were performed for all analysed multiplets, and their average values are presented in Figs. 6-8 by dotted lines. The calculated values are converted into angular frequency units. The slope of the theoretical Stark halfwidth increase along the homologous sequence is slightly higher than the slope of experimental results (full line in Fig. 6). The ratio of the Xe II theoretical Stark halfwidth average value over that of $\mathrm{Ne}$ II is 1.56 . The reason for this small disagreement is a discrepancy of experimental and theoretical results for Ne II, where the experimental results are always higher, on average by a factor of 1.4 .

The same calculations were performed for the multiplets belonging to the $\left({ }^{3} \mathrm{P}\right) n \mathrm{p}-\left({ }^{3} \mathrm{P}\right) n$ d transitions, but only for the $\mathrm{Ne}$ II and Ar II lines. The calculated results are presented by a dotted line in Fig. 8. For Kr II and Xe II, some data on perturbing levels which are necessary for MSE calculations,

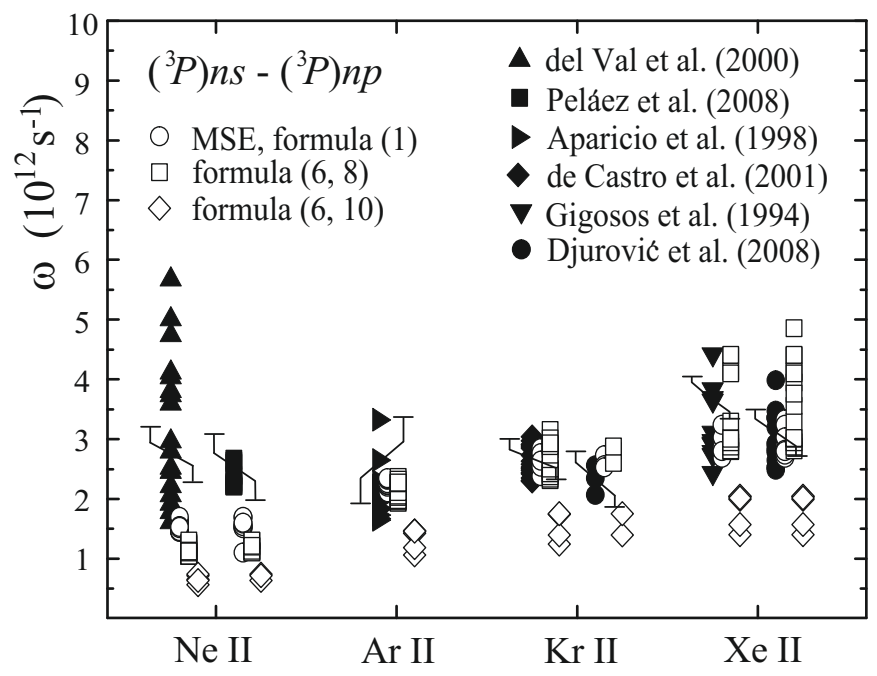

Fig. 9. Comparison of the measured and calculated Stark halfwidths along the homologous sequence for the $\left({ }^{3} \mathrm{P}\right) n \mathrm{~s}-\left({ }^{3} \mathrm{P}\right) n \mathrm{p}$ transitions.

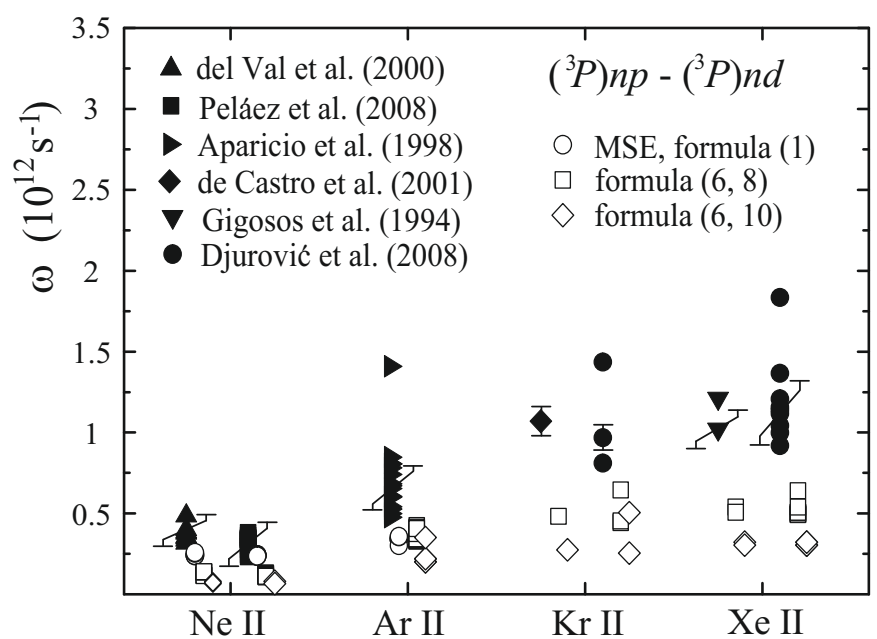

Fig. 10. Comparison of the measured and calculated Stark halfwidths along the homologous sequence for the $\left({ }^{3} \mathrm{P}\right) n \mathrm{p}-\left({ }^{3} \mathrm{P}\right) n \mathrm{~d}$ transitions.

are missing in the NIST database, as well as other literature (Hansen \& Persson 1987; Sugar \& Musgrove 1991; Saloman 2004, 2007), so the calculations cannot be performed properly. Calculated Stark halfwidth results qualitatively agree in agreement with the experimental ones, the increase of the halfwidth for Ar II is obvious. The ratio between the experimental and calculated halfwidths is not as good as for the $\left({ }^{3} \mathrm{P}\right) n \mathrm{~s}-\left({ }^{3} \mathrm{P}\right) n \mathrm{p}$ transitions. For Ne II, this ratio is 1.5 , while it is 1.6 for Ar II.

The comparison of the experimental results and the calculations for all analysed spectral lines for the $\left({ }^{3} \mathrm{P}\right) n \mathrm{~s}-\left({ }^{3} \mathrm{P}\right) n \mathrm{p}$ transitions is shown in Fig. 9 and for the $\left({ }^{3} \mathrm{P}\right) n \mathrm{p}-\left({ }^{3} \mathrm{P}\right) n \mathrm{~d}$ transitions in Fig. 10. The calculated values are converted into angular frequency units. For the analysis, we included both experimental and calculated data for all the lines mentioned in Table 1. The error bars over the black experimental points are given to show the typical magnitude of this parameter.

Figure 9 shows the same experimental results as Fig. 6, except that here the results for all observed multiplets from one paper are given in the same column. It is obvious that for the $\left({ }^{3} \mathrm{P}\right) n \mathrm{~s}-\left({ }^{3} \mathrm{P}\right) n \mathrm{p}$ transitions, the MSE calculations obtained by Eq. (1) (Dimitrijević \& Konjević 1980) fit well for the Ar II, Kr II and Xe II lines, while for Ne II the MSE formula gives a slightly 


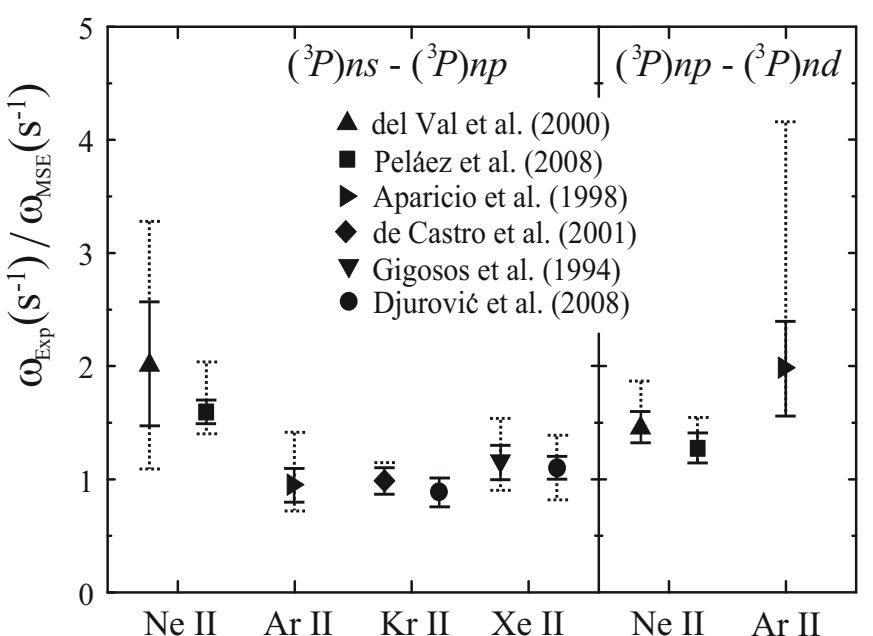

Fig. 11. Ratios of the experimental and MSE calculated Stark halfwidths (Eq. (1)). The full line error bars indicate the minimal and maximal ratio values. Only in one or two cases these maximal and minimal values are higher or lower, which is represented with dotted line error bars.

lower value in comparison to the experimental results. For Ne II all three calculations, i.e. MSE and calculations made by simplified formula Eq. (6) (Dimitrijević \& Konjević 1987) with two different normalisation factors $(8,10)$, give lower results than the experimental ones. For the other three ions, Eq. (6) with the normalisation factor (8) gives values that fit the experimental results well, similar to the MSE calculations, only with a slightly more dispersed results. The values calculated from Eq. (6) with the normalisation factor (10) are in all cases lower than the experimental results, and as the other two calculated results. This is expected because the approximation used in Dimitrijević \& Popović (1989) to derive the normalisation factor (10) neglects the contribution of the lower energy level to the total halfwidth of the line. Here it should be pointed out that the calculations using Eq. (6) with the normalisation factor (10) were made for the multiplets, and not for separate lines, due to approximation (9).

Figure 10 shows the comparison of the experimental and theoretical results of the Stark halfwidth increase along the homologous sequence for the $\left({ }^{3} \mathrm{P}\right) n \mathrm{p}-\left({ }^{3} \mathrm{P}\right) n$ d transitions. It is derived in the same way as Fig. 9. For these transitions, all three calculations give similar values which are lower than the experimental results, sometimes even two or three times. A similar conclusion as for the $\left({ }^{3} \mathrm{P}\right) n \mathrm{~s}-\left({ }^{3} \mathrm{P}\right) n \mathrm{p}$ transitions can be drawn here concerning the calculations with Eq. (6) with normalisation factor (10).

The ratios between the experimental and the MSE (Dimitrijević \& Konjević 1987) calculated Stark halfwidth results for both the $\left({ }^{3} \mathrm{P}\right) n \mathrm{~s}-\left({ }^{3} \mathrm{P}\right) n \mathrm{p}$ and $\left({ }^{3} \mathrm{P}\right) n \mathrm{p}-\left({ }^{3} \mathrm{P}\right) n \mathrm{~d}$ transitions are given in Fig. 11. As already mentioned for the $\left({ }^{3} \mathrm{P}\right) n \mathrm{p}-\left({ }^{3} \mathrm{P}\right) n \mathrm{~d}$ transitions the calculations were performed only for the Ne II and Ar II spectral lines due to the lack of perturbing levels necessary for the MSE calculations. The minimal and maximal values of the experimental and calculated halfwidths are presented in Fig. 11 with full line error bars for all considered experimental data. Most of the ratios for both the $\left({ }^{3} \mathrm{P}\right) n \mathrm{~s}-\left({ }^{3} \mathrm{P}\right) n \mathrm{p}$ and $\left({ }^{3} \mathrm{P}\right) n \mathrm{p}-\left({ }^{3} \mathrm{P}\right) n \mathrm{~d}$ transitions are between 0.8 and 2.5 . There are only one or two ratio values that are represented by dotted line error bars in Fig. 11. This is not unusual for the comparison of the experimental results and MSE calculations for spectral lines of noble gases. Similar agreements or disagreements were already found by the authors of the modified semiempirical formula himself (Popović \& Dimitrijević 1996). A large

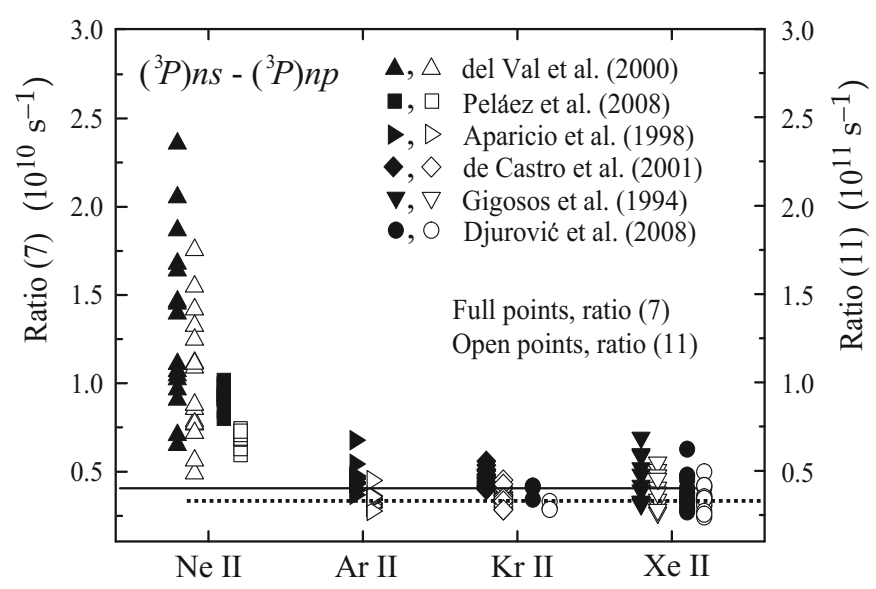

Fig. 12. Ratios (7) and (11) applied to the experimental Stark halfwidth values for the $\left({ }^{3} \mathrm{P}\right) n \mathrm{~s}-\left({ }^{3} \mathrm{P}\right) n \mathrm{p}$ transitions. The full and dotted horizontal line represent the average values of ratios (7) and (11), respectively, for Ar II, Kr II and Xe II.

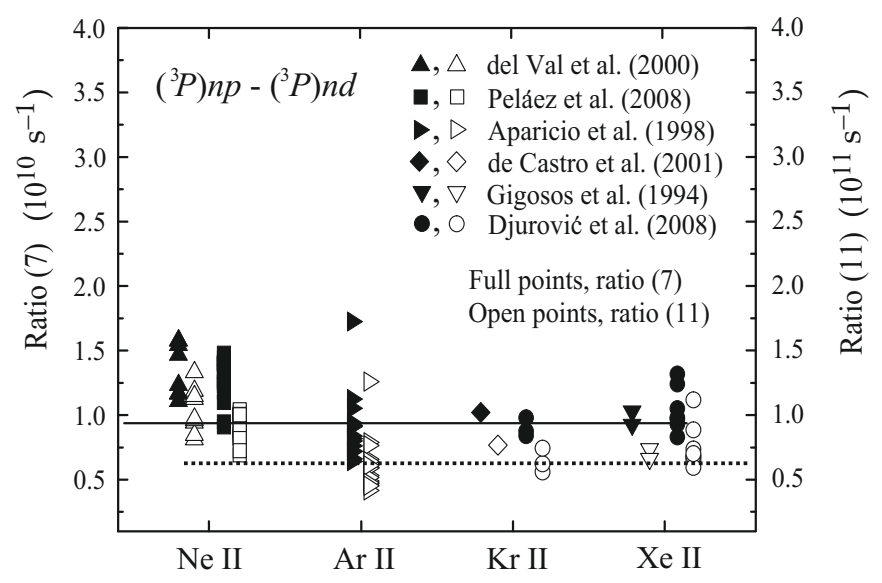

Fig. 13. Ratios (7) and (11) applied to experimental Stark halfwidth values for the $\left({ }^{3} \mathrm{P}\right) n \mathrm{p}-\left({ }^{3} \mathrm{P}\right) n \mathrm{~d}$ transitions. The full and dotted horizontal line represent the average values of ratios (7) and (11), respectively, for Ar II, Kr II and Xe II.

discrepancy was found only for Ne II (del Val et al. 2000), which was already commented on above, and for one value for Ar II (Aparicio et al. 1998). The ratio between the experimental results and the calculations with Eq. (6) was not analysed here, because the calculations made by the simplified Eq. (6) always give lower results, sometimes even twice as low as the MSE calculations. This is evident from Fig. 10.

The validity of the approximations made to obtain the normalisation factors $(8,10)$ can be checked by applying the ratios (7) and (11) to experimental data. The evolution of these ratios along the homologous sequence for the $\left({ }^{3} \mathrm{P}\right) n \mathrm{~s}-\left({ }^{3} \mathrm{P}\right) n \mathrm{p}$ and $\left({ }^{3} \mathrm{P}\right) n \mathrm{p}-\left({ }^{3} \mathrm{P}\right) n \mathrm{~d}$ transitions is shown in Figs. 12 and 13 respectively. For the $\left({ }^{3} \mathrm{P}\right) n \mathrm{~s}-\left({ }^{3} \mathrm{P}\right) n \mathrm{p}$ transitions both ratios $(7,11)$ are approximately constant for Ar II, Kr II and Xe II, while for Ne II these ratios are higher in both cases. For the $\left({ }^{3} \mathrm{P}\right) n \mathrm{p}-\left({ }^{3} \mathrm{P}\right) n \mathrm{~d}$ transitions the trend still exists, but the ratio values are more dispersed than for the $\left({ }^{3} \mathrm{P}\right) n \mathrm{~s}-\left({ }^{3} \mathrm{P}\right) n \mathrm{p}$ transitions. Again, both ratios $(7,11)$ have higher values for Ne II. The preservation of the constant values of ratios $(7,11)$ along the $\mathrm{Ar}$ II, $\mathrm{Kr}$ II and $\mathrm{Xe}$ II sequence is illustrated by full lines for ratio (7) and dotted lines for ratio (11) in Figs. 12 and 13.

Most of the Stark halfwidth behaviour along the homologous sequence of ionized noble gases can be explained by the 


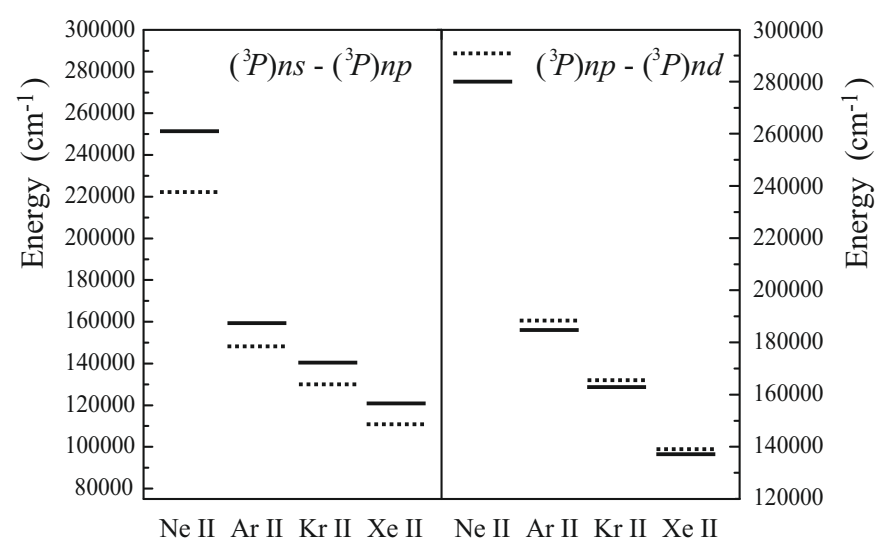

Fig. 14. Illustration of the relation between the upper energy levels of the observed transitions. Full lines represent the average values of the ${ }^{2}(\mathrm{DPS})^{\mathrm{o}}$ and ${ }^{4}(\mathrm{DPS})^{\circ}$ energy levels for the $\left({ }^{3} \mathrm{P}\right) n \mathrm{~s}-\left({ }^{3} \mathrm{P}\right) n \mathrm{p}$ transitions and the average values of the ${ }^{4}(\mathrm{FDP})$ energy levels for the $\left({ }^{3} \mathrm{P}\right) n \mathrm{p}-\left({ }^{3} \mathrm{P}\right) n \mathrm{~d}$ transitions. The dotted lines represent the corresponding average values of the closest perturbing levels.

ions' energy level structure. An illustration of the energy level structure for both the $\left({ }^{3} \mathrm{P}\right) n \mathrm{~s}-\left({ }^{3} \mathrm{P}\right) n \mathrm{p}$ and $\left({ }^{3} \mathrm{P}\right) n \mathrm{p}-\left({ }^{3} \mathrm{P}\right) n \mathrm{~d}$ transition is given in Fig. 14. For the analysis, the average values of the ${ }^{2}(\mathrm{DPS})^{\mathrm{o}}$ and ${ }^{4}(\mathrm{DPS})^{\mathrm{o}}$ energy levels were used for the $\left({ }^{3} \mathrm{P}\right) n \mathrm{~s}-\left({ }^{3} \mathrm{P}\right) n \mathrm{p}$ transitions and the average values of the ${ }^{4}$ (FDP) energy levels were used for the $\left({ }^{3} \mathrm{P}\right) n \mathrm{p}-\left({ }^{3} \mathrm{P}\right) n \mathrm{~d}$ transitions. At first sight, this averaging might seem too rough for such an analysis. Obviously, there are some variations from multiplet to multiplet and from line to line, but to arrive at some general conclusion these approximations are quite appropriate. Usually a broadening of the upper transition energy level contributes much more to the line halfwidth than the broadening of the lower energy level. Furthermore, the closest perturbing energy level has the most significant influence on the broadening of the observed upper or lower transition level. These are the reasons for employing this kind of analysis. The energy levels in Fig. 14 are expressed in $\mathrm{cm}^{-1}$ units, as given in the NIST database.

We point out that the MSE calculations were not performed for the $\mathrm{Kr}$ II and Xe II multiplets the $\left({ }^{3} \mathrm{P}\right) n \mathrm{p}-\left({ }^{3} \mathrm{P}\right) n \mathrm{~d}$ transitions due to the lack of perturbing levels data. In Fig. 14, the perturbing levels data are represented by dotted lines. This does not contradict the previous statement, because the data presented in Fig. 14 are simply an average value of the energy levels available in the NIST database. So, even if one of the perturbing levels is missing, the average value of the existing data can still be presented in the graph; but on the other hand the MSE calculations cannot be performed properly. An illustration of the situation is given in Djurović et al. (2006).

First of all, it is obvious from Figs. 6 and 8 as well as from Figs. 9 and 10 that the Stark halfwidths for the $\left({ }^{3} \mathrm{P}\right) n \mathrm{~s}-\left({ }^{3} \mathrm{P}\right) n \mathrm{p}$ transitions are lower than those for the $\left({ }^{3} \mathrm{P}\right) n \mathrm{p}-\left({ }^{3} \mathrm{P}\right) n \mathrm{~d}$ transitions. This can be explained by the closer position of the perturbing levels for the $\left({ }^{3} \mathrm{P}\right) n \mathrm{p}-\left({ }^{3} \mathrm{P}\right) n \mathrm{~d}$ case, which can be seen in Fig. 14. A very low increase of the experimental Stark halfwidths along the homologous sequence is observed for the $\left({ }^{3} \mathrm{P}\right) n \mathrm{~s}-\left({ }^{3} \mathrm{P}\right) n \mathrm{p}$ transitions. With the exception of $\mathrm{Ne}$ II, the differences between the upper transition level and the corresponding closest perturbing level are almost equal for $\mathrm{Ar}$ II, Kr II and Xe II (see Fig. 14). For the $\left({ }^{3} \mathrm{P}\right) n \mathrm{p}-\left({ }^{3} \mathrm{P}\right) n \mathrm{~d}$ transitions, a clear increase of Stark halfwidths along the homologous sequence is observed. In this case, the closest perturbing level are getting closer to the upper transition levels when going from $\mathrm{Ne}$ II to Xe II. In conclusion, all these general trends can be explained in this way. There is only one small discrepancy. One would expect a slightly lower experimental Stark halfwidth (del Val et al. 2000; Peláez et al. 2008) for the $\left({ }^{3} \mathrm{P}\right) n \mathrm{~s}-\left({ }^{3} \mathrm{P}\right) n \mathrm{p}$ transitions of Ne II, due to a larger difference between the average upper transition energy level and the closest perturbing level compared to the difference for Ar II (see Figs. 8 and 14). These higher halfwidth values cause a discrepancy in the analysis which is presented in Fig. 12. If we take into account all available corresponding experimental data as presented in Fig. 1, the discrepancy disappears.

\section{Conclusions}

We analysed the experimental Stark halfwidth behaviour for the $\left({ }^{3} \mathrm{P}\right) n \mathrm{~s}-\left({ }^{3} \mathrm{P}\right) n \mathrm{p}$ and $\left({ }^{3} \mathrm{P}\right) n \mathrm{p}-\left({ }^{3} \mathrm{P}\right) n \mathrm{~d}$ transitions along the homologous sequence of ionized noble gases. For this analysis we used all experimental results available in the literature, but paid special attention to the results obtained in Laboratory of Plasma Spectroscopy in Valladolid. It is obvious from Figs. 1 to 5 that Stark halfwidth regularities do exist. At the same time there is a significant dispersion of the experimental data. We showed that even dispersed experimental halfwidth results follow the regular behaviour for multiplets, supermultiplets or transition arrays as established in Wiese \& Konjević (1982).

Our multiplet by multiplet analysis shows that there is only a slight increase of the Stark halfwidth values along the homologous sequence from Ne II to Xe II for the $\left({ }^{3} \mathrm{P}\right) n \mathrm{~s}-\left({ }^{3} \mathrm{P}\right) n \mathrm{p}$ transition. Using the linear fit of the average Stark halfwidth values for the multiplets the ratio Stark halfwidths(Xe II)/Stark halfwidths $(\mathrm{Ne}$ II $)=1.25$ were obtained. For the multiplets of the $\left({ }^{3} \mathrm{P}\right) n \mathrm{p}-\left({ }^{3} \mathrm{P}\right) n \mathrm{~d}$ transition, a clear increase of the Stark halfwidths along the homologous sequence was observed, as were the ratio Stark halfwidths(Xe II)/Stark halfwidths(Ne II) = 3.08. As one can see, the data fit an approximately straight line. In cases where very close perturbing levels exist, highly irregular behaviour along the homologous sequence can occur. These deviations are described for Xe II in Peláez et al. (2009a).

The modified semiempirical formula MSE Eq. (1) (Dimitrijević \& Konjević 1980) and the simplified modified semiempirical formula (Dimitrijević \& Konjević 1987) were used for the theoretical analysis of the Stark halfwidth regularity along the homologous sequence. The MSE calculated results agree well with the experimental data for the $\left({ }^{3} \mathrm{P}\right) n \mathrm{~s}-\left({ }^{3} \mathrm{P}\right) n \mathrm{p}$ transitions, which can be seen from Fig. 9. For the $\left({ }^{3} \mathrm{P}\right) n \mathrm{p}-\left({ }^{3} \mathrm{P}\right) n \mathrm{~d}$ transitions, the MSE calculations for $\mathrm{Ne}$ II and Ar II give 1.4 and 2 times lower Stark halfwidth values respectively (see Fig. 10). For $\mathrm{Kr}$ II and Xe II the MSE calculations were not performed due to the lack of the corresponding perturbing energy levels data. Independently of these ratios one can conclude that the MSE formula is still useful for Stark halfwidths estimations. Furthermore, the MSE calculations are much easier and faster than the full quantum mechanical calculations.

Stark halfwidth calculations with the simplified Eq. (6) with the normalisation factor (8) give similar results to those obtained with MSE. This is expected, because the condition for simplified MSE formula application, i.e. that very close perturbing levels do not exist, was satisfied for all considered transitions. Further analysis shows that the normalisation factors $(8,10)$, which depend on the effective quantum number and the ionization energy (Figs. 12 and 13), give a constant ratio halfwidth/normalisation factor for both the $\left({ }^{3} \mathrm{P}\right) n \mathrm{~s}-\left({ }^{3} \mathrm{P}\right) n \mathrm{p}$ and $\left({ }^{3} \mathrm{P}\right) n \mathrm{p}-\left({ }^{3} \mathrm{P}\right) n$ d transitions for argon, kripton and xenon, while for the analysed neon data 
the factors seem to be a little underestimated. When taking into account all available experimental data as presented in Fig. 1, one can see that normalisation factors work well in this case, as well.

In conclusion, if we ignore the relatively small differences between the line halfwidths within multiplets or supermultiplets, the obtained Stark halfwidth trends for the lines belonging to the $\left({ }^{3} \mathrm{P}\right) n \mathrm{~s}-\left({ }^{3} \mathrm{P}\right) n \mathrm{p}$ and $\left({ }^{3} \mathrm{P}\right) n \mathrm{p}-\left({ }^{3} \mathrm{P}\right) n \mathrm{~d}$ transitions along the homologous sequence of ionized noble gases can be used for data interpolation purposes. The MSE calculations in conjunction with the analysis of the relation between the closest perturbing levels and the corresponding upper transition level (Fig. 14) can explain the determined behaviour of the experimental Stark halfwidth data. Still, one should keep in mind that even when dealing with ions with complex spectra, by increasing the effective principal quantum number along the homologous sequence, on average an increasing density of perturbing states and a declining energy separation between the transition and perturbing levels occur.

This kind of the Stark halfwidth trend analysis is useful for astrophysical purposes, i.e. for the stellar spectra analysis and synthesis, stellar plasma investigations, diagnostics and modelling, the abundance studies of stellar atmospheres etc. Interpolations of the experimental data as well as simple theoretical calculations are especially important in cases when a large number of data is necessary. As an example, data for more than $10^{6}$ transitions including spectral line parameters are needed for the calculations of stellar opacities (Pradham 1987; Seaton 1988).

We only analysed the trends for the $\left({ }^{3} \mathrm{P}\right) n \mathrm{~s}-\left({ }^{3} \mathrm{P}\right) n \mathrm{p}$ and $\left({ }^{3} \mathrm{P}\right) n \mathrm{p}-\left({ }^{3} \mathrm{P}\right) n \mathrm{~d}$ transitions along the homologous sequence with the under assumption that all Stark halfwidth measurements were performed at the same electron temperature. We employed the frequently used assumption that the Stark halfwidth depends weakly on the electron temperature. However, the temperature varied in the range from 8000 to $82000 \mathrm{~K}$ in experiments of other authors and in the range from 15000 to $27000 \mathrm{~K}$ in our experiments with Ar II, Kr II and Xe II, while for Ne II the temperature varied from 25000 to $45000 \mathrm{~K}$.

Finally, only the trends of the Stark halfwidths were shown, but for numerical halfwidth values one should use the original data from the corresponding references already mentioned.

Acknowledgements. We thank S. González for his work on the experimental device, the Spanish Ministerio de Ciencia y Tecnología and the Consejería de Educación y Cultura de la Junta de Castilla y Leon for their financial support under contracts Nos. FIS2005-03155 and VA015A05 respectively. J. A Aparicio wants to express his personal acknowledgement to the ONCE for help. S. Djurović thanks to Ministry of Science and Development of Republic of Serbia for support in Project 141024.

\section{References}

Abbas, A., Basha, T. S., \& Abdel-Aal, Z. A. 1988, Jap. J. Appl. Phys., 27, 804 Adelman, S. J. 1992, MNRAS, 258, 167

Aparicio, J. A., Gigosos, M. A., González, V. R., et al. 1998, J. Phys. B: At. Mol. Phys., 31, 1029

Bates, R. D., \& Damgaard, A. 1949, Phi. Trans. Roy. Soc. London Ser. A, 242, 101

Behringer, K., \& Thoma, P. 1978, J. Quant. Spectrosc. Radiat. Trans., 20, 615

Bertuccelli, G., \& Di Rocco, H. O. 1991, Phys. Scr., 44, 138

Bertuccelli, G., \& Di Rocco, H. O. 1993, Phys. Scr., 47, 747

Bertuccelli, D., Bertuccelli, G., \& Di Rocco, H. O. 1991a, Phys. Scr., 43, 469

Bertuccelli, D., Bertuccelli, G., \& Di Rocco, H. O. 1991b, Rev. Sci. Instrum., 62, 966

Bidelman, W. P. 1964, Proc. Symp., 26, Utrecht, Netherlands, ed. H. Hubert (London: IAU, Academic), 229

Blagojević, B., Popović, M. V., \& Konjević, N. 1999, Phys. Scr., 59, 374

Boeker, T., Krabbe, A., \& Storey, J. W. V. 1998, ApJ, 498, L115
Bord, D. J., Cowley, C. R., Hubrig, S., \& Bidelman, W. P. 2003, Am. Astron. Soc. Meeting, Nashville, USA, 202, 3210

Cardelli, J. A., \& Mayer, S. 1997, ApJ, 477, L57

Cartledge, S. I. B., Meyer, D. M., \& Lauroesch, J. T. 2003, ApJ, 597, 408

de Castro, A., Aparicio, J. A., del Val, J. A., González, V. R., \& Mar, S. 2001, J. Phys. B: At. Mol. Phys., 34, 3275

Chapelle, J., Sy, A., Cabannes, F., \& Blandin, J. 1968a, J. Quant. Spectrosc. Radiat. Trans., 8, 1201

Chapelle, J., Sy, A., Cabannes, F., \& Blandin, J. 1968b, J. C. R. H. Acad. Sci. Ser. B, 266, 1513

Davies, J. T., \& Vaughan, J. M. 1963, ApJ, 137, 1302

Dimitrijević, M. S. 1985, A\&A, 145, 439

Dimitrijević, M. S., \& Konjević, N. 1980, J. Quant. Spectrosc. Radiat. Trans., 24, 451

Dimitrijević, M. S., \& Konjević, N. 1984, Z. Naturforsch, 39a, 553

Dimitrijević, M. S., \& Konjević, N. 1987, A\&A, 172, 345

Dimitrijević, M. S., \& Popović, M. M. 1989, A\&A, 217, 201

Dimitrijević, M. S., Mihajlov, A. A., \& Popović, M. M. 1987, A\&A, 70, 57

Dinerstein, H. L. 2001, ApJ, 550, L223

Di Rocco, H. O. 1990, J. Appl. Phys, 68, 3732

Djeniže, S., Malešević, M., Srećković, A., Milosavljević, M., \& Purić, J. 1989,

J. Quant. Spectrosc. Radiat. Trans., 42, 429

Djurović, S., Peláez, R. J., Ćirišan, M., Aparicio, J. A., \& Mar, S. 2006, J. Phys. B: At. Mol. Phys., 39, 2901

Djurović, S., Peláez, R. J., Ćirišan, M., Aparicio, J. A., \& Mar, S. 2008, Phys. Rev. A, 78, 042507

Dzierzega, K., \& Musiol, K. 1994, J. Quant. Spectrosc. Radiat. Trans., 52, 747

Esteban, C., Peimbert, M., García-Rojas, J., et al. 2004, MNRAS, 355, 229

Gigosos, M. A, Mar, S., Pérez, C., \& de la Rosa, I. 1994, Phys. Rev. E, 49, 1575

Griem, H. R. 1964, Plasma spectroscopy (New York: McGraw Hill)

Griem, H. R. 1968, Phys. Rev. A, 165, 258

Griem, H. R. 1974, Spectral Line Broadening by Plasmas (New York: Academic) Griem, H. R., Baranger, M., Kolb, A. C., \& Oertel, G. K. 1962, Phys. Rev., 125, 177

Hansen, J. E., \& Persson, W. 1973, Phys. Scr., 8, 197

Hansen, J. E., \& Persson, W. 1987, Phys. Scr., 36, 602

Iglesias, C. A., Rogers, F. J., \& Wilson, B. G. 1990, ApJ, 360, 221

Iglesias, E. J., Ghosh, J., Elton, R. C., \& Griem, H. R. 2006, J. Quant. Spectrosc.

Radiat. Trans., 98, 101

Jalufka, N. W., Oertel, G. K., \& Ofelt, G. S. 1966, Phys. Rev. Lett., 16, 1073

Keenan, F. P., Bates, B., Dufton, P. L., Holmgren, D. E., \& Gilheany, S. 1990, ApJ, 348, 322

Klein, L. 1973, J. Quant. Spectrosc. Radiat. Trans., 13, 567

Konjević, N., \& Wiese, W. L. 1976, J. Phys. Chem. Ref. Data, 5, 259

Konjević, N., \& Pittman, T. L. 1987, J. Quant. Spectrosc. Radiat. Trans., 37, 311

Konjević, N., \& Wiese, W. L. 1990, J. Phys. Chem. Ref. Data, 19, 1307

Konjević, N., \& Uzelac, N. I. 1990, J. Quant. Spectrosc. Radiat. Trans., 44, 61

Konjević, N., Labat, J., Cirković, Lj., \& Purić, J. 1970, Z. Phys., 235, 35

Konjević, N., Dimitrijević, M. S., \& Wiese, W. L. 1984, J. Phys. Chem. Ref. Data, 13, 649

Konjević, N., Lesage, A., Fuhr, J. R., \& Wiese, W. L. 2002, J. Phys. Chem. Ref. Data, 31, 819

Kramida, A. E., \& Nave, G. 2006, Eur. Phys. J., 39, 331

Kurucz, R. L. 1994, Atomic Line Data, Kurucz CD-ROM 23 (Cambridge, Mass: $\mathrm{SAO})$

Labat, J., Djeniže, S., Ćirković, Lj., \& Purić, J. 1974, J. Phys. B: At. Mol. Phys., 7,1174

Lahuis, F., van Dishoeck, E. F., Blake, G. A., et al. 2007, ApJ, 665, 492

Lanz, T., Dimitrijević, M. S., \& Artru, M. C. 1988, A\&A, 192, 249

Lanz, T., Cunha, K., Holtzman, J., \& Hubeny, I. 2008, ApJ, 678, 1342

Lefloch, B., Cernicharo, J., Cabrit, S., et al. 2003, ApJ, 590, L41

Leitherer, C. 2010, in Stellar Populations - Planning for the Next Decade, ed. G. Bruzual, \& S. Charlot, IAU Symp., 262, 73

Lesage, A. 2009, New Astr. Rev., 52, 471

Lesage, A., Abadie, D., \& Miller, M. H. 1989, Phys. Rev. A, 40, 1367

Manola, S., Konjević, N., Richou, J., Leburn, J. L., \& Lesage, A. 1988, Phys. Rev. A, 38, 5742

Miller, M. H., Lessage, A., \& Purić, J. 1980, ApJ, 239, 410

Miller, M. H., Lesage, A., \& Abadie, D. 1982, Phys. Rev. A, 25, 2064

Milosavljević, V., Djeniže, S., Dimitrijević, M. S., \& Popović, L. Č. 2000, Phys. Rev. E, 62, 4137

Milosavljević, V., Dimitrijević, M. S., \& Djeniže, S. 2001, ApJS, 135, 115

Minnhagen, L. 1962, Arkiv för Fysik, 21, 415

Nick, K. P., \& Helbig, V. 1986, Phys. Scr., 33, 55

NIST, Atomic spectra database, http://physics.nist.gov./asd

Oertel, G. K., \& Shomo, L. P. 1968, ApJS, 16, 175

Pascucci, I., Hollenbach, D., Najita, J., et al. 2007, ApJ, 663, 383

Peláez, R. J., Djurović, S., Ćirišan, M., et al. 2008, ApJ, 687, 1423 
Peláez, R. J., Djurović, S., Ćirišan, M., Aparicio, J. A., \& Mar, S. 2009a, J. Phys. B: At. Mol. Phys., 42, 125002

Peláez, R. J., Ćirišan, M., Djurović, S., Aparicio, J. A., \& Mar, S. 2009b, A\&A, 507, 1697

Pellerin, S., Musiol, K., \& Chapelle, J. 1997, J. Quant. Spectrosc. Radiat. Trans., 57,377

Peytremann, E. 1972, A\&A, 17, 76

Pittman, T. L., \& Konjević, N. 1986, J. Quant. Spectrosc. Radiat. Trans., 35, 247

Platiša, M., Dimitrijević, M. S., \& Konjević, N. 1978, A\&A, 67, 103

Popenoe, C. H., \& Shumaker, J. B. Jr. 1965, J. Res. Nat. Bur. Stand. A, 69, 495

Popović, L. Č., \& Dimitrijević, M. S. 1996, ApJS, 116, 359

Popović, L. Č., \& Dimitrijević, M. S., \& Ryabchikova, T. 1999, A\&A, 350, 719

Pradham, A. K. 1987, Phys. Scr., 35, 840

Purić, J., \& Lakićević, I. S. 1982, Phys. Lett. A, 91, 345

Purić, J., \& Šćepanović, M. 1999, ApJ, 521, 490

Purić, J., Lakićević, I., \& Glavonjić, V. 1980, Phys. Lett. A, 76, 128

Purić, J., Ćuk, M., \& Lakićević, I. S. 1985, Phys. Rev. A, 32, 1106

Purić, J., Djeniže, S., Srećković, A., Labat, J., \& Ćirković, Lj. 1987, Phys. Rev. A, 35, 2111

Purić, J., Dojčinović, I. P., Nikolić, M., et al. 2008, ApJ, 680, 803

Reyna Almandos, J., Bredice, F., Raineri, M., \& Gallardo, M. 2009, Phys. Scr., T134, 014018

Richou, J., Manola, S., Leburn, J. L., \& Lesage, A. 1984, Phys. Rev. A, 29, 3181

Roberts, D. E. 1966, Phys. Lett., 22, 417

Roberts, D. E. 1968, J. Phys. B: At. Mol. Phys., 1, 53

Ryabchikova, T. A., Malanushenko, V. P., \& Adelman, S. J. 1999, A\&A, 351, 963

Sadakane, K., Takada-Hidal, M., Takeda, Y., et al. 2001, Pub. Astron. Soc. Japan, 53,1223
Saloman, E. B. 2004, J. Phys. Chem. Ref. Data, 33, 765

Saloman, E. B. 2007, J. Phys. Chem. Ref. Data, 36, 215

Sapar, A., Aret, A., Sapar, L., \& Poolamäe, R. 2009, New Astron Rev 53 240, Proceedings of the VII Serbian Conference on Spectral Line Shapes (VII SCSLSA) held in Zrenjanin, Serbia June 15th-19th [arXiv : 0909. 3798]

Seaton, M. J. 1988, J. Phys. B: At. Mol. Phys., 21, 3033

Sherbini, Th. M. El., \& Zaki, M. A. 1978, J. Phys. B: At. Mol. Phys., 11, 2061

Skinner, C. H. 2009, Phys. Scr., T134, 014022

Striganov, A. R., \& Sventitskii, N. S. 1968, Tables of Spectral Lines of Neutral and Ionized Atoms (New York: Plenum)

Sugar, J., \& Musgrove, A. 1991, J. Phys. Chem. Ref. Data, 20, 859

Uzelac, N. I., \& Konjević, N. 1989, J. Phys. B: At. Mol. Phys., 22, 2517

Uzelac, N. I., Glenzer, S., Konjević, N., Hey, J. D., \& Kunze, H.-J. 1993, Phys. Rev. E, 47, 3623

Vaessen, P. H. M., van Engelen, J. M. L., \& Bleize, J. J. 1985, J. Quant. Spectrosc. Radiat. Trans., 33, 51

del Val, J. A., Mar, S., Gigosos, M. A, et al. 1998, Jpn. J. Phys., 37, 4147

del Val, J. A., Aparicio, J. A., \& Mar, S. 2000, ApJ, 536, 998

del Val, J. A., Peláez, R. J., Mar, S., et al. 2008, Phys. Rev. A, 77, 012501

Vitel, Y., \& Skowronek, M. 1987, J. Phys. B: At. Mol. Phys., 20, 6477

Vitel, Y., Skowronek, M., Dimitrijević, M. S., \& Popović, M. M. 1988, A\&A, 200, 285

Werner, K. 1984, A\&A, 139, 237

Werner, K., Deetjen, J. L., Dreizler, S., et al. 2003, in Stellar Atmosphere Modeling, ed. I. Hubeny, D. Mihalas, \& K. Werner (San Francisco: ASP), ASP Conf. Ser., 288, 31

Whitford, A. E. 1962, AJ, 67, 608

Wiese, W. L., \& Konjević, N. 1982, J. Quant. Spectrosc. Radiat. Trans., 28, 185 